This manuscript has been authored by UT-Battelle, LLC under Contract No. DE-AC05-00OR22725 with the U.S. Department of Energy. The United States Government retains and the publisher, by accepting the article for publication, acknowledges that the United States Government retains a non-exclusive, paid-up, irrevocable, world-wide license to publish or reproduce the published form of this manuscript, or allow others to do so, for United States Government purposes. The Department of Energy will provide public access to these results of federally sponsored research in accordance with the DOE Public Access Plan (http:/lenergy.gov/downloads/doe-public-access-plan). 


\title{
Examining the multi-scale complexity and the crystallographic hierarchy of isothermally treated bainitic and martensitic structures
}

Keywords: Steels; Bainite; Martensite; Atom Probe Tomography; Carbide precipitation.

D. De-Castro ${ }^{\mathrm{a}}$, R. Rementeria ${ }^{\mathrm{a}, \mathrm{b}}$, J. Vivas $^{\mathrm{a}, \mathrm{c}}$, T. Sourmail ${ }^{\mathrm{d}}$, J.D. Poplawsky ${ }^{\mathrm{e}}$, E. Urones-Garrote ${ }^{\mathrm{f}}$, J.A. Jimenez $^{\text {a }}$, C. Capdevila ${ }^{\mathrm{a}}$ and F.G. Caballero ${ }^{\mathrm{a},{ }^{*}}$

${ }^{a}$ Department of Physical Metallurgy, National Center for Metallurgical Research (CENIM-CSIC), Madrid, Spain

${ }^{\mathrm{b}}$ ArcelorMittal Global R\&D, SLab-Steel Labs, Calle Marineros 4, 33490, Avilés, Asturias, Spain

${ }^{\mathrm{c}}$ IK4 LORTEK, Ordizia, Guipuzkoa, Spain

${ }^{\mathrm{d}}$ Asco Industries Research (CREAS), BP 70045 Hagondange, France

${ }^{\mathrm{e}}$ Center for Nanophase Materials Sciences, Oak Ridge National Laboratory, Oak Ridge, TN, USA

f Spanish National Centre for Electron Microscopy (CNME), Facultad de Ciencias Químicas, Universidad Complutense de Madrid, Madrid, Spain.

\begin{abstract}
In this work, differences and similarities between bainitic and martensitic structures obtained by isothermal heat treatments such as austempering, quench and partitioning (Q\&P) and quench and tempering (Q\&T), are investigated by multiple techniques including X-ray diffraction, electron backscatter diffraction, scanning and transmission electron microscopy and atom probe tomography. Results reveal that analogous lath-like ferritic structures with similar austenite content can be achieved by adjusting the isothermal holding temperature. However, certain variability in hardness is recorded, which is consistent with differences on the precipitation state revealed by the nano-scale examination of the structure, and with dissimilar crystallographic size distribution of ferritic grains.
\end{abstract}

\section{Introduction}

Nowadays, different treatments are considered to achieve complex ferritic structures with a controlled retained austenite volume fraction that improves the Transformation-Induced-Plasticity (TRIP) effect and the work-hardening of high strength bainitic and martensitic structures. Among these heat treatments, Quenching and Partitioning (Q\&P) is receiving increasing attention as a new heat treatment to produce high strength steels containing a mixture of martensite (fresh and/or tempered), bainitic ferrite and retained austenite, with a desirable combination of strength, ductility 
and toughness [1-7]. This process involves quenching the austenite between the martensite start (Ms) and martensite finish (Mf) temperatures, followed by a partitioning treatment to enrich the remaining austenite with carbon, thereby stabilizing it to room temperature [8]. In high silicon steels, similar structures can be also achieved by more simple heat treatments such as an isothermal bainitic treatment, conventionally known as austempering, which results in a mixture of ultra-fine or nano-scale bainitic ferrite (depending on the transformation temperature), retained austenite, and some martensite, with an optimum combination of strength and toughness [9-13]; or a traditional quench and tempering (Q\&T), a well-established approach for producing high-strength martensitic and maraging steels [14].

The distinction between phases present after the application of this type of heat treatments is difficult in multiphase steels due to the morphological similarities between transformation products. Both bainite and martensite reactions involves a sudden, ordered movement of iron atoms, which is accompanied by a given crystal correspondence, the classic Kurdjumov-Sachs (K-S) or NishiyamaWasserman $(\mathrm{N}-\mathrm{W})$ orientation relationships between the austenite and ferrite lattices, and a macroscopic shape strain of the transformed structure $[15,16]$, which is described as an invariant plane strain with a relatively large shear component.

Bainite, as martensite, exhibits a characteristic hierarchy sub-structure of aggregates of ferrite plates. The transformation product is restricted to the prior austenite grain which is divided into packets, i.e. the group of plates of ferrite with the same habit plane, and each packet is further subdivided into blocks, i.e. the group of plates of ferrite of the same orientation or slightly misoriented [17-19].

All the displacive transformation products in steel, such as Widmanstätten ferrite, bainitic ferrite and martensite, occur in the form of thin plates to minimize strain energy [20]. In the martensite reaction, where the shape strain is elastically accommodated and thermoelastic equilibrium occurs, the aspect ratio of the plate is adjusted so that the strain energy is consistent with the driving force [21], while thermoelastic equilibrium has not been demonstrated for bainite. The soft and hard impingement of the carbon diffusion field associated with individual plates growing parallel in a sheave of bainite restricts their thickness and controls the spacing between plates of bainitic ferrite [22]. In addition, the shape deformation accompanying bainitic ferrite growth is accommodated by plastic relaxation of the surrounding austenite, mechanically weaker at higher transformation temperatures. Plates of bainitic ferrite are thus halted in their growth by the resulting dislocations debris, becoming thinner at lower temperatures when the austenite is harder [23].

On the other hand, carbon supersaturation and tetragonality are not exclusive of martensite. Significant amounts of carbon in bainitic ferrite have also been observed in microstructures transformed below $350^{\circ} \mathrm{C}$, confirming that, as martensite, bainitic ferrite grows without diffusion of 
carbon [24-26]. The high level of carbon supersaturation in bainite is also accompanied by a change in symmetry of the unit cell from cubic to tetragonal [27]. Eventually, carbon supersaturation is relieved by partitioning to austenite, as in Q\&P structures, and a chain of interconnected reactions including carbon segregation to lattice defects, carbon atom clustering, carbon ordering, and carbide precipitation, are activated in a form identical to the tempering of martensite [23, 28-31].

Recently, the nature of the different lath-like microstructural features obtained in isothermal treatments, particularly below Ms in a Fe-0.2C-3.51Mn-1.52Si (wt.-\%) steel, has been determined as bainitic ferrite or martensite by comparing the volume fractions of the product phases with the morphology (size and shape) of the specific features using scanning electron microscopy (SEM) and electron backscatter diffraction (EBSD) [32]. Results showed that bainitic ferrite appears as thin units with acicular or irregularly shaped laths, whereas martensite appears as laths with a sharp tip and as relatively large elongated laths with wavy boundaries containing protrusions. The appearance of these protuberances was explained by the formation of bainitic ferrite in isothermal treatments below Ms, which might also lead to the formation of wavy boundaries in such martensitic laths [33]. It is therefore difficult to identify all these subtle differences to discriminate non-equilibrium ferritic structures.

Likewise, high resolution electron microscopy is required to see the orientation of the fine carbides to differentiate lower bainite and tempered martensite. Martensite and bainite microstructures are similar, containing lath-like phases and small carbides and can be hard to distinguish, making it difficult to explain the expected differences in properties.

In this work, complex ferritic structures obtained by different heat treatments (austempering, Q\&T and Q\&P) are investigated by multiple characterisation techniques including X-ray diffraction (XRD), EBSD, SEM, transmission electron microscopy (TEM) and atom probe tomography (APT). Comparable bainitic and martensitic structures with similar hardness and retained austenite content can be achieved by decreasing the treatment temperature. Only carbon atom distribution to the nano-scale and their crystallographic hierarchy sub-structure allow differentiation of bainite and martensite treated at low temperatures.

Table 1. Chemical composition of 100CrSiMn6-5-4 steel.

\begin{tabular}{lllllllllll}
\hline & $\mathrm{C}$ & $\mathrm{Si}$ & $\mathrm{Mn}$ & $\mathrm{Ni}$ & $\mathrm{Cr}$ & $\mathrm{Mo}$ & $\mathrm{Cu}$ & $\mathrm{S}$ & $\mathrm{P}$ & $\mathrm{Al}$ \\
\hline wt.\% & 0.98 & 1.27 & 0.99 & 0.11 & 1.36 & 0.02 & 0.14 & 0.01 & 0.01 & 0.04 \\
\hline at.\% & 4.34 & 2.41 & 0.96 & 0.10 & 1.39 & 0.01 & 0.12 & 0.02 & 0.02 & 0.08
\end{tabular}




\section{Material and experimental procedure}

The alloy studied is a high-carbon/high-silicon steel, specifically designed for bearings operating in severe loading conditions in contaminated environments $[34,35]$, that transforms at low temperatures $\left(135-350^{\circ} \mathrm{C}\right)$ to a mixture of very fine bainitic ferrite laths and retained austenite. The chemical composition of this alloy is shown in Table 1 . The material was obtained from industrially produced bars, hot-rolled from ingots to a diameter of $65 \mathrm{~mm}$.

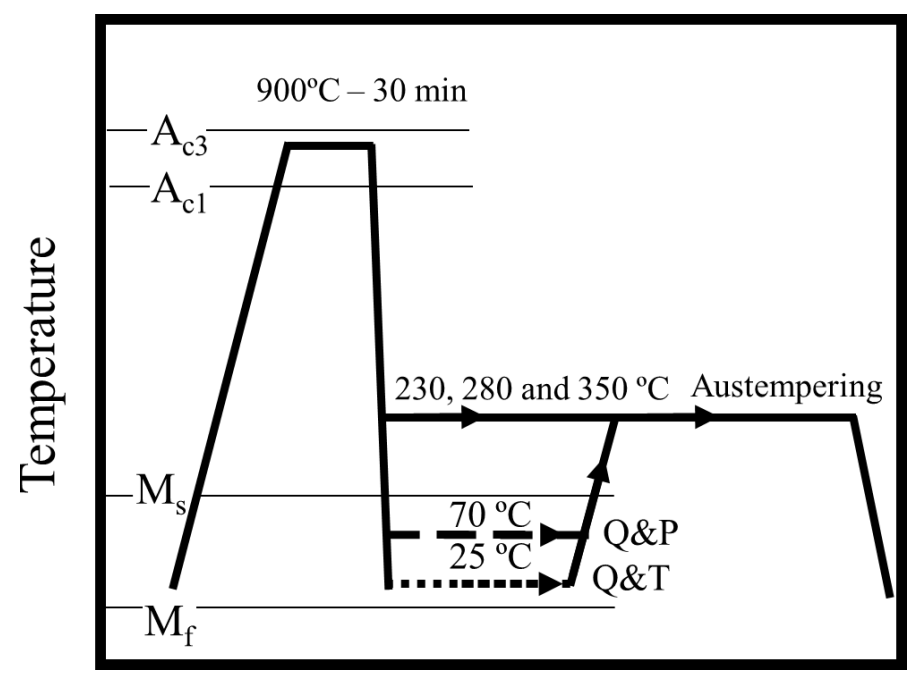

Figure 1. Scheme of the heat treatments performed to obtain bainitic, and Q\&P and Q\&T martensitic structures in 100CrSiMn6-5-4 steel. $\mathrm{Ms}=(136 \pm 7){ }^{\circ} \mathrm{C}$ and $\mathrm{Mf}<25^{\circ} \mathrm{C}$.

Heat treatments were performed in the furnace of a Bahr $805 \mathrm{D}$ high-resolution dilatometer on cylindrical samples of $5 \mathrm{~mm}$ in diameter and $10 \mathrm{~mm}$ long. Three different treatments, austempering, Q\&P and Q\&T, with identical austenitising conditions $\left(900{ }^{\circ} \mathrm{C}\right.$ for $30 \mathrm{~min}$ ) were performed (see scheme in Figure 1) to obtain bainitic and martensitic structures containing retained austenite in the studied steel. Given the austenitisation temperature, traces of undissolved primary cementite are also expected to be presented in the structure.

Bainitic structures were obtained by an isothermal heat treatment at 230,280 and $350{ }^{\circ} \mathrm{C}$. On the other hand, Q\&P and Q\&T martensitic structures were obtained by quenching at $70^{\circ} \mathrm{C}$ and room temperature (RT), respectively, followed by a reheating to the same selected temperatures (i.e. 230, 280 and $350{ }^{\circ} \mathrm{C}$ ). The corresponding holding times are listed in Table 2. In all cases, after the isothermal treatment, samples were air quenched to room temperature.

Microstructure examination was performed on a HITACHI S-4800 field emission gun (FEG) SEM, operating at $7 \mathrm{kV}$ or $10 \mathrm{kV}$. Observations were made in the cross section of dilatometry samples. Moreover, EBSD orientation maps were acquired by means of a FEG-SEM ZEISS Auriga Compact equipped with an Oxford NordlysNano EBSD detector and assisted by the AZtecHKL acquisition 
and OXFORD HKL CHANNEL 5 analysis software, operating at $15 \mathrm{kV}$. Analyses were performed in the longitudinal section of dilatometric samples. A $60 \mu \mathrm{m} \times 45 \mu \mathrm{m}$ area was scanned for all samples with a step size of $0.07 \mu \mathrm{m}$. Body-centred cubic (bcc) ferrite, face-centred cubic (fcc) austenite and orthorhombic cementite phases were successfully indexed.

Table 2. Heat treatments performed in 100CrSiMn6-5-4 steel and quantitative data on microstructure. $\mathrm{T}_{\mathrm{Q}}$ is the quench temperature; $\mathrm{T}_{\text {iso }}$ and tiso are the treatment temperature and holding time, respectively.

\begin{tabular}{llllll}
\hline Sample & $\mathrm{T}_{\mathrm{Q}},{ }^{\circ} \mathrm{C}$ & $\mathrm{T}_{\mathrm{iso}},{ }^{\circ} \mathrm{C}$ & $\mathrm{t}_{\mathrm{iso}}, \mathrm{h}$ & $\begin{array}{l}\text { Austenite Content } \\
(\%) \pm 3\end{array}$ & $\begin{array}{l}\text { Hardness } \\
\mathrm{HV} 30\end{array}$ \\
\hline As-Quenched & $\mathrm{RT}$ & - & - & 29 & $795 \pm 3$ \\
\hline B-230 & 230 & 230 & 35 & 15 & $680 \pm 5$ \\
B-280 & 280 & 280 & 15 & 26 & $562 \pm 6$ \\
B-350 & 350 & 350 & 5 & 47 & $387 \pm 2$ \\
\hline QP-230 & 70 & 230 & 100 & 15 & $715 \pm 4$ \\
QP-280 & 70 & 280 & 4 & 21 & $683 \pm 5$ \\
QP-350 & 70 & 350 & 2 & 28 & $643 \pm 9$ \\
\hline QT-230 & RT & 230 & 80 & 13 & $750 \pm 3$ \\
QT-280 & RT & 280 & 2 & 15 & $725 \pm 5$ \\
QT-350 & RT & 350 & 2 & 20 & $698 \pm 8$ \\
\hline
\end{tabular}

XRD analysis was used to determine the fraction of retained austenite and other structural parameters, such as the lattice parameters, microstrain, and crystallite size. For this purpose, specimens were prepared by a standard grinding and polishing procedure, which included a final polish with $1 \mu \mathrm{m}$ diamond paste and several cycles of etching and polishing to remove the deformed layer. XRD measurements were carried out with a Bruker AXS D8 diffractometer equipped with a Co X-ray tube, Goebel mirror optics and a LynxEye Linear Position Sensitive detector. XRD data were collected over a $2 \theta$ range of 35 to $135^{\circ}$ with a step size of $0.015^{\circ}$. The lattice parameters of austenite and ferrite were determined from the Rietveld method [36]. The analysis of the diffraction line profiles for deriving quantitative information on crystallite size and microstrain was performed by means of the double-Voigt approach, in which both the crystallite size and strain are comprised of Lorentzian and Gaussian broadening components [37].

A JEOL JEM3000F TEM operated at $200 \mathrm{kV}$ was used for the TEM experiments. High-resolution TEM (HR-TEM) images were acquired for structural characterization and further simulated with CaRIne Crystallography 4.0 commercial software. Thin foils were prepared by twin jet 
electropolishing using a solution of $5 \%$ perchloric acid in methanol at $20{ }^{\circ} \mathrm{C}$ and a $50 \mathrm{~V}$ operating voltage.

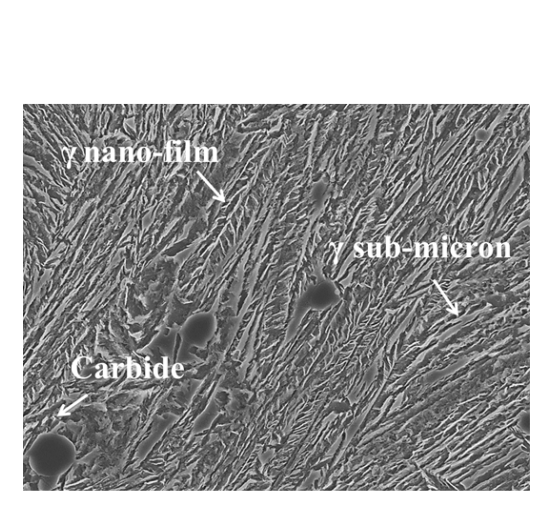

(a)

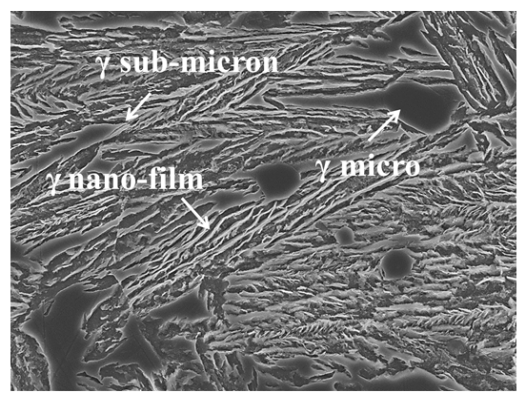

(b)

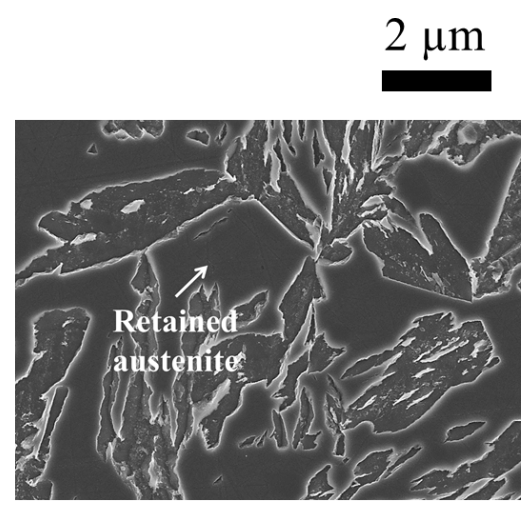

(c)

Figure 2. FEG-SEM micrographs for samples austempered at (a) $230{ }^{\circ} \mathrm{C}$, (b) $280{ }^{\circ} \mathrm{C}$ and (c) $350{ }^{\circ} \mathrm{C}$.

Finally, APT needle-shaped samples were cut from bulk material and electropolished with the standard double layer and micropolishing methods, followed by focused ion beam (FIB) annular milling to improve the needle shape [38, 39]. Atom probe analyses were performed in a local electrode atom probe LEAP 4000X HR operating in voltage-pulse mode with a specimen temperature of $50 \mathrm{~K}$, a pulse repetition rate of $200 \mathrm{kHz}$, and a pulse fraction of 0.2 .

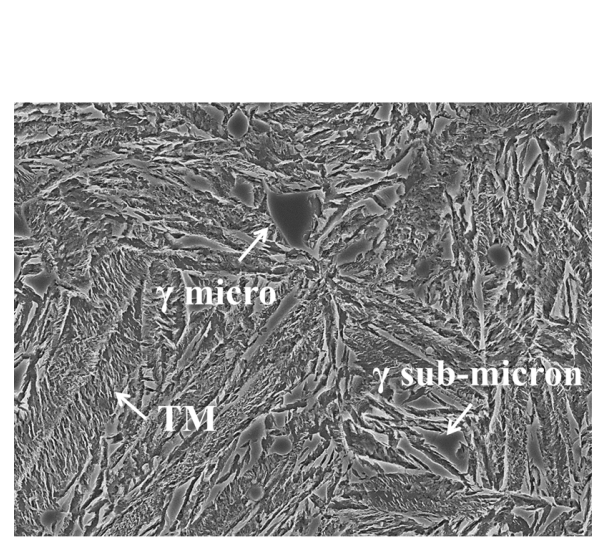

(a)

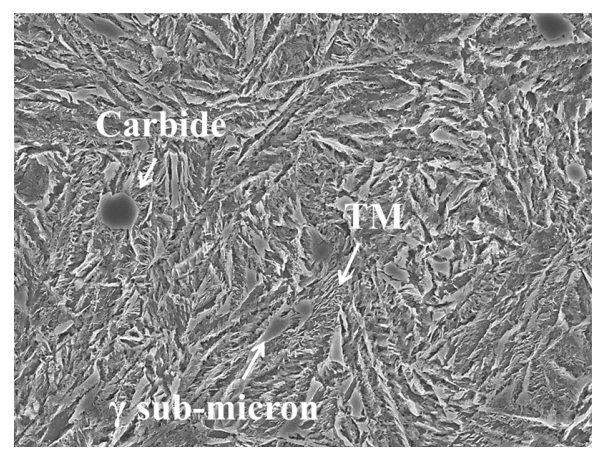

(c)

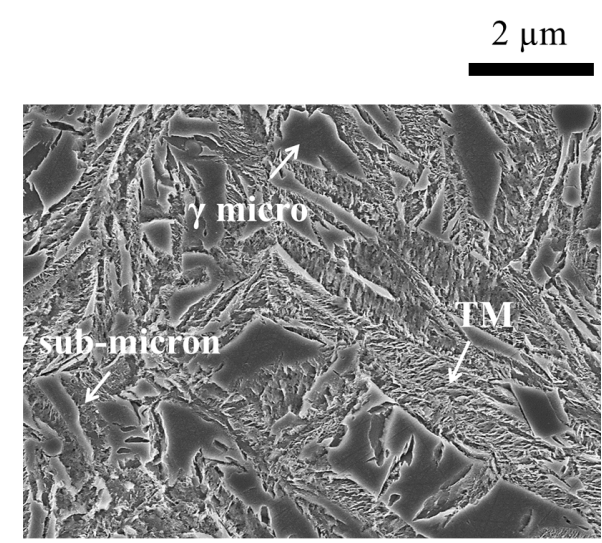

(b)

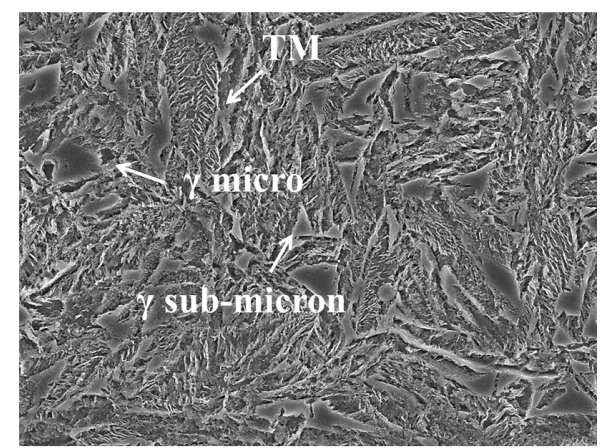

(d) 
Figure 3. FEG-SEM micrographs for Q\&P samples treated at (a) $230^{\circ} \mathrm{C}$, and (b) $350{ }^{\circ} \mathrm{C}$; and Q\&T samples treated at (c) $230^{\circ} \mathrm{C}$, and (d) $350{ }^{\circ} \mathrm{C}$. TM denotes tempered martensite.

\section{Results and discussion}

\subsection{Micro-scale examination of the structures}

Figure 2 shows micrographs of bainitic structures containing bainitic ferrite, different retained austenite content (15-47\%) depending on the transformation temperature $\left(230,280\right.$ and $\left.350{ }^{\circ} \mathrm{C}\right)$ and undissolved primary cementite. Austenite $(\gamma)$ is dispersed in a fine ferritic matrix as two forms: (i) micron/submicron blocks of retained austenite located between the ferrite packets and (ii) nanoscale films of austenite which are retained between the ferrite lath subunits within a given packet or block. From Figure 2 (c) and hardness values listed in Table 2, the effect of the heat treatment temperature on the microstructure is evident: the sample austempered at higher temperature, $350{ }^{\circ} \mathrm{C}$, exhibits much coarser microstructural features and higher austenite content than those treated at 230 and $280^{\circ} \mathrm{C}$.

Figure 3 shows some examples of FEG-SEM micrographs for Q\&P and Q\&T martensitic structures treated at temperatures of $230^{\circ} \mathrm{C}$ and $350^{\circ} \mathrm{C}$, Microstructures consist of tempered martensite, bainitic ferrite, retained austenite, and undissolved primary cementite. For both heat treatment routes, the micrographs do not reveal clear differences in the microstructures obtained at the treated partitioning or tempering temperatures.

During reheating, carbon migrates from martensite (formed during quenching) to the surrounding austenite, resulting in slightly higher retained austenite fractions at higher temperatures (See results listed in Table 2). Bainite can also be formed during the partitioning or tempering stage. Nevertheless, the amount of bainite obtained in Q\&T structures is expected to be lower than that in Q\&P because the austenite fraction retained at RT after quenching is lower than the residual austenite fraction at the interrupted quenching temperature $\left(70{ }^{\circ} \mathrm{C}\right)$ in Q\&P treatment.

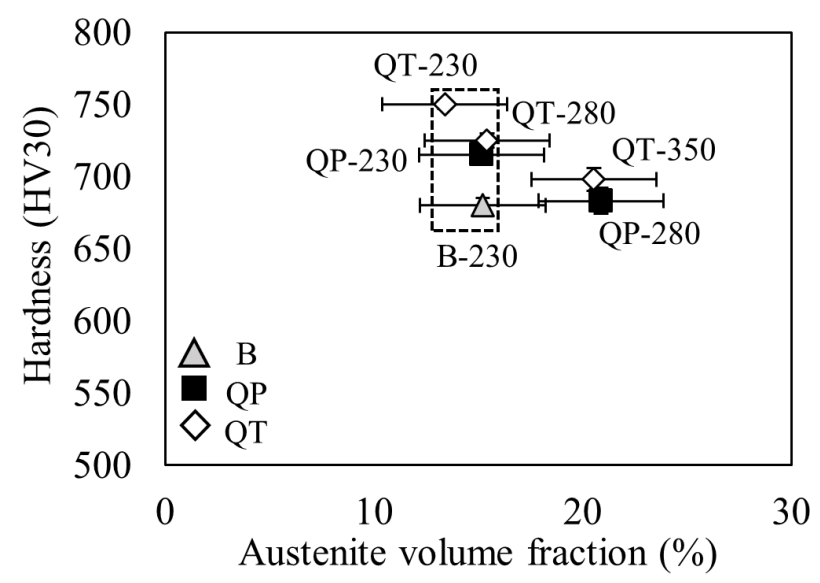


Figure 4. Quantitative data on certain bainitic and Q\&P and Q\&T martensitic structures in 100CrSiMn6-5-4 steel. Square box selects those bainitic and martensitic structures with similar austenite content (13-15\%).

It is clear from preliminary microstructural examination that bainite reveals far greater sensitivity to the treatment temperature than martensite. Indeed, the measured retained austenite content varies from $15 \%$ to over $50 \%$ when increasing the transformation temperature from 230 to $350{ }^{\circ} \mathrm{C}$, while for Q\&P and Q\&T structures, retained austenite content remains in the vicinity of $13-28 \%$ (see data in Table 2). Since austenite is a soft and ductile phase, the presence of this phase causes a decrease in the hardness of lath-like ferritic structures. What is remarkable is that comparable bainitic and martensitic structures in terms of hardness and retained austenite can be achieved by decreasing the isothermal temperature. As the square box in Figure 4 illustrates, bainitic structures austempered at $230{ }^{\circ} \mathrm{C}$ contain approximately the same retained austenite fraction $(13-15 \%)$ as that in Q\&P and Q\&T martensitic structures treated at the same temperature, and only a maximum difference of 70 $\mathrm{HV}$ is detected among them.

In addition, martensitic structures with almost identical austenite content and hardness values can be achieved just adjusting the partitioning and tempering temperatures. Thus, equivalent structures are achieved after Q\&P at $230^{\circ} \mathrm{C}$ and $\mathrm{Q} \& \mathrm{~T}$ at $280^{\circ} \mathrm{C}$ with a retained austenite content of $15 \%$ and a hardness value of $\sim 720 \mathrm{HV}$; and after Q\&P at $280^{\circ} \mathrm{C}$ and Q\&T at $350^{\circ} \mathrm{C}$ with a retained austenite content of $\sim 20 \%$ and a hardness value of $\sim 690 \mathrm{HV}$. It is noteworthy that with only a difference of $50{ }^{\circ} \mathrm{C}$ analogous martensitic structures can be achieved by Q\&P and simpler Q\&T heat treatments.

In an attempt to explain the systematic higher hardness values detected in martensitic structures when compared with bainitic structures with similar retained austenite content, the amount of undissolved primary cementite was determined by XRD. Likewise, the structural characteristics that could explain these differences in hardness such as the tetragonality in ferrite, microstrain and crystallite size of the structure were estimated using the same technique. Table 3 collects the structural data results of the Rietveld XRD pattern refinements for the selected bainitic and martensitic structures with similar austenite content (13-15\%). Bainitic structures austempered at $230{ }^{\circ} \mathrm{C}$ exhibit similar cementite content, and comparable tetragonality values to selected Q\&P and Q\&T tempered martensitic structures. It should be noted that tetragonality values reported in this table resembles those values reported elsewhere [27] for bainitic ferrite transformed at similar temperatures $\left(220\right.$ and $\left.250^{\circ} \mathrm{C}\right)$ in high carbon high silicon steels, but they are an order of magnitude lower than the tetragonality reported for fresh martensite in the same steels [27].

On the other hand, both the average volume-weighted crystallite size of the bainitic ferrite plates and the measured microstrain $(\varepsilon)$, both determined by the double-Voigt approach, are comparable. 
Although in some cases the crystallite size and plate thickness can be equivalent, a recent study [40] demonstrated that they are not directly related in low temperature bainite. The dislocation network generated on bainitic ferrite during the bainitic transformation creates small-angle domain boundaries which subdivide the bainitic ferrite into coherent domains smaller in size than the actual plate thickness. Although these domains do not induce any visible contrast in TEM observations, XRD line profile analysis measures the actual size of these objects. Dislocations are also responsible of heterogeneous microstrain. Other sources of strain can be triple junctions of grain or sub-grain boundaries, stacking faults, twin boundaries, etc. [41]. In addition, dislocation density as estimated from microstrain and crystallite size $[42,43]$ is given in Table 3 . These values are analogous in all the structures, and in general terms, similar to those measured for low temperature bainite and martensitic microstructures elsewhere [23, 29, 44].

Table 3. XRD results of selected bainitic and martensitic structures with similar austenite content (13-15\%). $\varepsilon$ stands for microstrain and $\rho$ is the dislocation density in ferrite.

\begin{tabular}{|c|c|c|c|c|c|c|}
\hline Sample & $\begin{array}{l}\text { Austenite } \\
\text { Content } \\
(\%) \pm 3\end{array}$ & $\begin{array}{l}\text { Cementite } \\
\text { Content } \\
(\%) \pm 3\end{array}$ & $\begin{array}{l}\text { Tetragonality } \\
\text { in ferrite } \\
c / a \pm 0.0002\end{array}$ & $\begin{array}{l}\text { Ferrite } \\
\text { Crystallite } \\
\text { size } \\
(\mathrm{nm}) \pm 2\end{array}$ & $\begin{array}{l}\varepsilon \times 10^{-3} \\
\pm 0.2\end{array}$ & $\begin{array}{l}\rho^{\times 10^{15}} \\
\left(\mathrm{~m}^{-2}\right) \pm 10 \%\end{array}$ \\
\hline B-230 & 15 & 4 & 1.009 & 32 & 2.5 & 2.4 \\
\hline QP-230 & 15 & 2 & 1.008 & 27 & 2.4 & 2.6 \\
\hline QT-230 & 13 & 3 & 1.008 & 26 & 2.4 & 2.8 \\
\hline QT-280 & 15 & 3 & 1.008 & 26 & 2.1 & 2.5 \\
\hline
\end{tabular}

\subsection{Nano-scale examination of the structures}

Microstructural differences between bainitic and martensitic samples treated at low temperature go beyond those observed by XRD analyses and SEM examination, and higher magnification techniques are required to reveal possible differences on precipitation state that could explain the higher hardness values detected in bainitic and martensitic structures treated at the same temperature.

The strength of lath-like ferritic structures can be factorized into components consisting of the intrinsic strength of pure annealed iron $\left(\sigma_{F e}\right)$, solid solution strengthening of both substitutional $\left(\sigma_{S S}\right)$ and interstitial $\left(\sigma_{C}\right)$ alloying elements, dislocation strengthening, precipitation strengthening and grain size effects according to [45]:

$\sigma=\sigma_{F e}+\sigma_{C}+\sum_{i} \sigma_{S S}^{i}+k_{\rho} \rho^{0.5}+k_{p} V_{p} \Delta^{-1}+k_{L} \bar{L}^{-1}$ 
where $k_{\rho}, k_{p}$ and $k_{L}$ are constants for the contributions to strength of dislocations, precipitates and grain size, respectively. According to Table 3, the first four terms in Eq. 1 should have a similar value for the structures here studied. Therefore, differences in hardness could be attributed to i) precipitation strengthening, which is a function of the volume fraction of carbides $\left(V_{p}\right)$ and the average distance between a carbide particle and its second or third near neighbours $(\Delta)$, and ii) grain size contribution, which are inversely proportional to the effective grain size of the matrix $(\bar{L})$.

In general, $\bar{L}$ is related to the ferrite plate thickness. However, as already mentioned, the ferrite crystallite size and ferrite plate thickness are not always directly related [40]. Instead, the crystallize size, defined as the smallest undistorted region in a crystal, can be used as a proper effective grain size of the matrix $(\bar{L})$. As Table 3 shows, crystallite size values of B230, Q\&P230 and Q\&T230 samples are similar, therefore, differences in hardness cannot be explain by the grain size contribution in Eq. (1). Examination of the carbides strengthening would help to understand the changes in hardness due to the different heat treating routes.

Table 4: Nature of particles, average carbon content determined by APT across the ferrite/carbide interface and calculated partitioning coefficient $\left(K_{X}^{\alpha / \theta \text { or } \varepsilon}\right)$ for a given alloying element $(\mathrm{X})$ in bainitic and martensitic structures in 100CrSiMn6-5-4 steel.

\begin{tabular}{|c|c|c|c|}
\hline Sample & $\begin{array}{l}\text { Clusters } \\
{[\mathrm{C}] \text {, at.\% }}\end{array}$ & $\begin{array}{l}\text { Carbides } \\
{[\mathrm{C}] \text {, at.\% }}\end{array}$ & $K_{X}^{\alpha / c a r b i d e}$ \\
\hline B-230 & $11.0 \pm 0.3(*)$ & $23.5 \pm 0.2$ & Si:0.9 $\pm 0.1 ; \mathrm{Cr}: 0.7 \pm 0.1 ; \mathrm{Mn}: 0.8 \pm 0.1$ \\
\hline \multirow[t]{9}{*}{ QT-230 } & $7.1 \pm 0.1$ & $17.1 \pm 0.3$ & Si:0.9 $\pm 0.2 ;$ Cr:0.8 $\pm 0.2 ;$ Mn:0.6 \pm 0.2 \\
\hline & $8.0 \pm 0.5$ & $22.2 \pm 0.1$ & Si: $1.0 \pm 0.1 ;$ Cr: $0.7 \pm 0.1 ; \mathrm{Mn}: 0.7 \pm 0.1$ \\
\hline & $7.9 \pm 0.5$ & $23.4 \pm 0.3$ & Si:0.9 $\pm 0.1 ;$ Cr: $0.7 \pm 0.1 ;$ Mn: $0.9 \pm 0.2$ \\
\hline & $10.4 \pm 0.4$ & $24.8 \pm 0.7$ & Si:0.9 $\pm 0.2 ; \mathrm{Cr}: 0.9 \pm 0.3 ; \mathrm{Mn}: 0.9 \pm 0.3$ \\
\hline & $13.9 \pm 0.2$ & $24.8 \pm 0.4$ & $\mathrm{Si}: 1.1 \pm 0.1 ; \mathrm{Cr}: 0.9 \pm 0.2 ; \mathrm{Mn}: 0.9 \pm 0.2$ \\
\hline & \multirow[t]{4}{*}{$(9.5 \pm 2.8)(* *)$} & $25.2 \pm 0.3$ & Si: $1.0 \pm 0.1 ;$ Cr: $0.8 \pm 0.1 ;$ Mn: $0.9 \pm 0.2$ \\
\hline & & $25.8 \pm 0.3$ & Si: $1.0 \pm 0.1 ;$ Cr: $0.8 \pm 0.1 ; \mathrm{Mn}: 0.9 \pm 0.2$ \\
\hline & & $27.6 \pm 0.2$ & Si:0.9 $\pm 0.1 ;$ Cr: $0.8 \pm 0.1 ;$ Mn: $0.9 \pm 0.1$ \\
\hline & & $31.8 \pm 0.30$ & Si:0.9 $\pm 0.1 ;$ Cr: $0.7 \pm 0.1 ; \mathrm{Mn}: 0.7 \pm 0.1$ \\
\hline \multirow[t]{5}{*}{ QT-350 } & $7.7 \pm 0.3$ & $20.2 \pm 0.4$ & Si: $1.1 \pm 0.2 ; \mathrm{Cr}: 0.7 \pm 0.1 ; \mathrm{Mn}: 0.7 \pm 0.1$ \\
\hline & \multirow{2}{*}{$9.9 \pm 0.1$} & $21.2 \pm 0.1$ & Si: $0.9 \pm 0.1 ;$ Cr: $0.8 \pm 0.1 ; \mathrm{Mn}: 0.7 \pm 0.1$ \\
\hline & & $22.2 \pm 0.3$ & Si: $1.2 \pm 0.1 ;$ Cr: $0.6 \pm 0.1 ; \mathrm{Mn}: 0.6 \pm 0.1$ \\
\hline & \multirow{2}{*}{$13.0 \pm 0.7$} & $24.2 \pm 0.6$ & Si: $1.4 \pm 0.3 ;$ Cr: $0.6 \pm 0.2 ; \mathrm{Mn}: 0.6 \pm 0.1$ \\
\hline & & $26.9 \pm 0.1$ & $\mathrm{Si}: 1.7 \pm 0.1 ; \mathrm{Cr}: 0.2 \pm 0.1 ; \mathrm{Mn}: 0.6 \pm 0.1$ \\
\hline
\end{tabular}




$\begin{array}{lll}(10.2 \pm 2.7)(* *) & 27.3 \pm 0.2 & \text { Si: } 1.1 \pm 0.1 ; \mathrm{Cr}: 0.6 \pm 0.1 ; \mathrm{Mn}: 0.8 \pm 0.1 \\ & 28.9 \pm 0.1 & \text { Si: } 1.4 \pm 0.1 ; \mathrm{Cr}: 0.6 \pm 0.1 ; \mathrm{Mn}: 0.7 \pm 0.1\end{array}$

$\left(^{*}\right)$ Error bars representing the statistical scatter in the APT composition profiles due to the number of ions in each range of the selected volume of analysis.

(**) Values in parentheses are mean values of the APT measurements listed inside the same cell. Their corresponding error bars are standard deviations of the mean value representing the dispersion of a collection of APT measurements.

The nature of the different carbides formed during austempering at $230{ }^{\circ} \mathrm{C}$ and after Q\&T at the same temperature in the studied steel was studied based on their average carbon content estimated from APT data with the use of concentration profiles and proximity histograms across carbideferrite interfaces $[30,31,46]$. Likewise, carbides present in the martensitic structure after Q\&T at $350^{\circ} \mathrm{C}$ was investigated by APT. As Figure 4 shows, this sample was also selected since it exhibits hardness values of $690 \mathrm{HV}$, similar to that in a bainitic structure austempered at $230{ }^{\circ} \mathrm{C}$, but contains higher amount of retained austenite (20\%). Examples of carbon atom maps showing carbon segregation across clusters and carbide particles are shown in Figures 5-7.

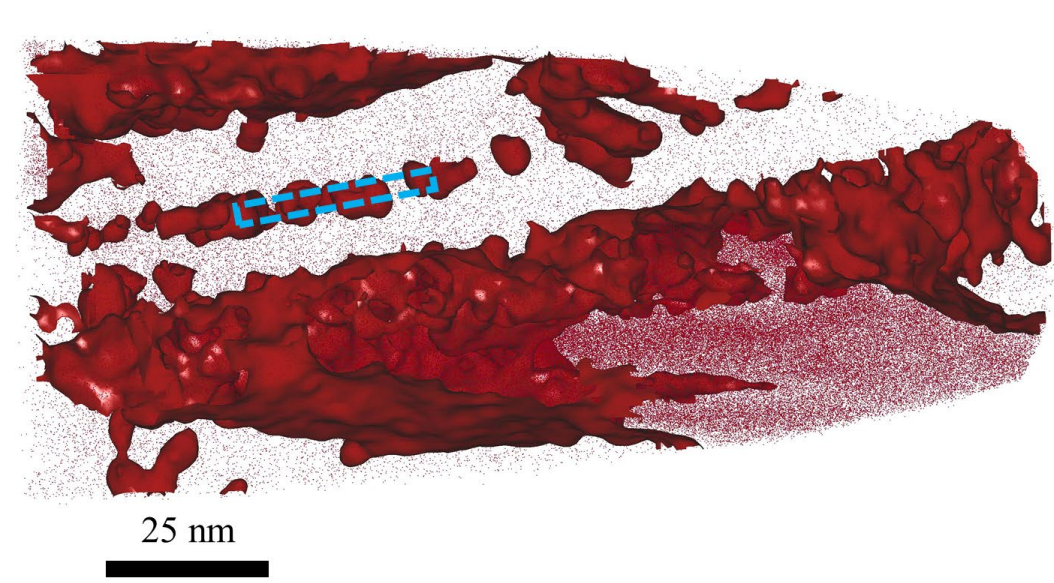

a)

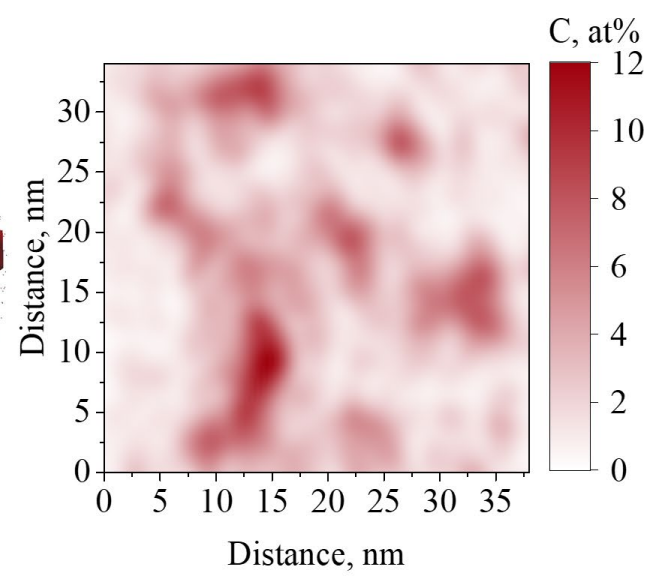

b)

Figure 5. Carbon atom map with superimposed carbon isoconcentration surfaces at 4 at.\% $\mathrm{C}$ for the bainitic ferrite austempered at $230^{\circ} \mathrm{C}$ and (b) $2 \mathrm{D}$ projection contour map of a $38 \times 34.5 \times 10 \mathrm{~nm}^{3}$ volume containing cluster particles marked by blue rectangle.

The average carbon content of the clusters and carbide particles observed in bainitic and martensitic structures in the studied steel is listed in Table 4. Carbon clusters, equivalent to the $\mathrm{Fe}_{16} \mathrm{C}_{2}$ structure with $\sim 11$ at.\% C, were identified in both bainitic and martensitic structures as a small (a few nano- 
meter in size) accumulation of carbon atoms dispersed throughout the ferrite matrix with a carbon content between 7-14 at. \% C. These particles did not exhibit clear evidence of substitutional solute partitioning across the interface. Carbon atom clusters formerly reported in tempered martensite have been considered to be the embryos for transitional carbide precipitation [47-51]. The origin of this carbon segregation at the nano-scale is thought to be associated to the tetragonality of carbon supersaturated ferritic structures and carbon segregation to lattice defects [31].

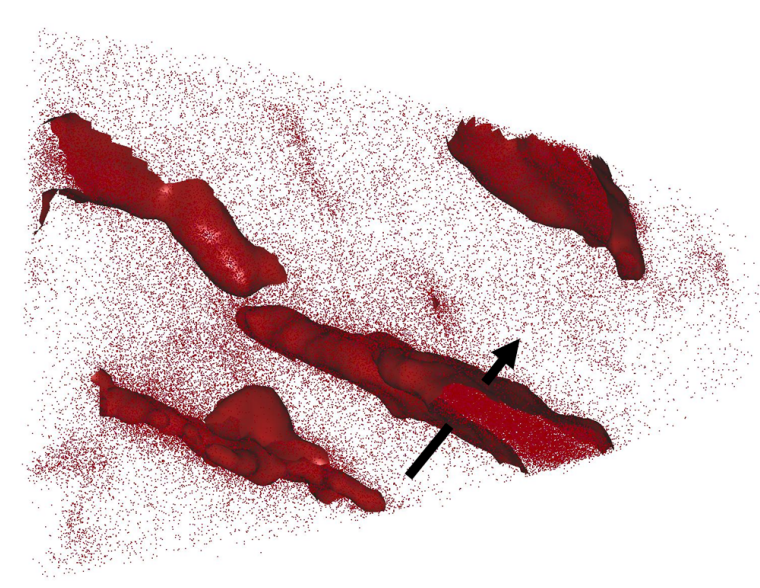

$25 \mathrm{~nm}$

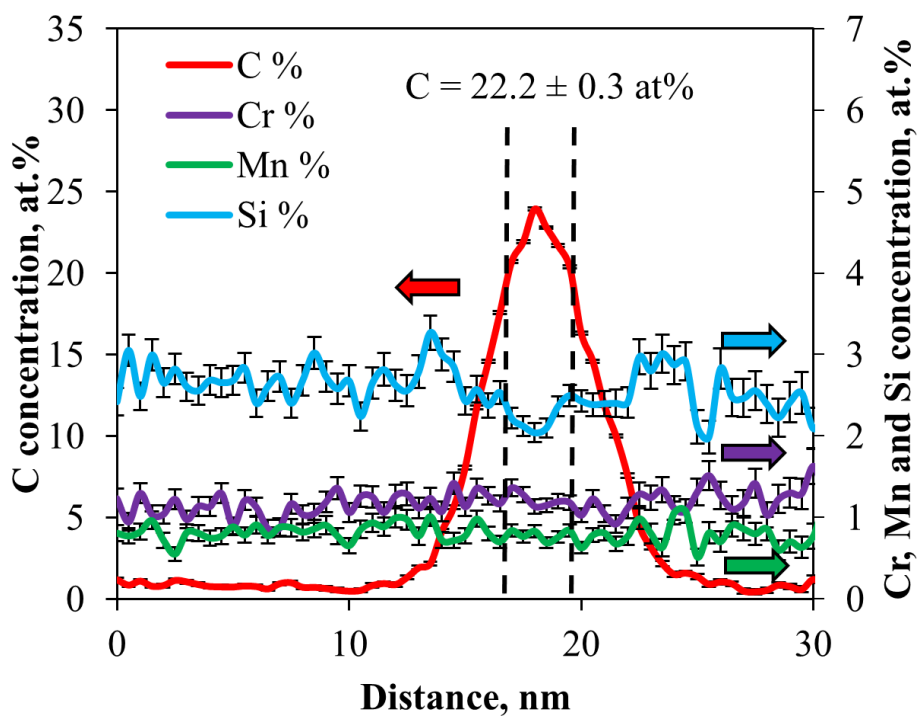

b)

Figure 6. (a) Carbon isoconcentration surfaces at 8 at. \% $\mathrm{C}$ superimposed with the carbon atom map, and (b) 1D concentration profile across a carbide particle, marked by the black arrow, in martensite after tempering at $230^{\circ} \mathrm{C}$ for 80 hours.

Carbides particles were also identified in martensitic structures as carbon enriched features with a carbon content higher than 14 at. \% (Figures 6 and 7) showing certain evidences of substitutional solute partitioning across the interface. Cementite ideally contains a carbon content of 25 at. \%; the detected underestimation of carbon content in cementite in Figure 6 and Table 4 is still an unresolved issue for this technique $[52,53]$. The extent of alloying element partitioning across the ferrite/carbide interface $K_{X}^{\alpha / \text { carbide }}$ listed in Table 4, was calculated as elsewhere [29], where $K_{X}^{\alpha / \text { carbide }}$ values close to 1 indicate the absence of solute partitioning, and values above and below 1 reveal solute depletion and enrichment within the carbide, respectively. In agreement with

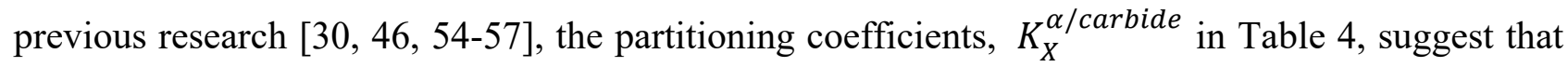
eventually silicon will deplete in carbides, meanwhile chromium and manganese are expected to progressively enrich across the interface. Likewise, $K_{X}^{\alpha / \text { carbide }}$ values show limited diffusivity of the substitutional elements compared to that of interstitials during bainite reaction and during 
tempering at $230{ }^{\circ} \mathrm{C}[58]$. As expected, increasing the tempering temperature from 230 to $350{ }^{\circ} \mathrm{C}$ in martensitic structures the redistribution of solutes is enhanced as the $K_{X}^{\alpha / \text { carbide }}$ values reveal. Particles with a carbon content close to 30 at. \% (Figure 7 and Table 4) can be identified as $\varepsilon$ carbides, a transition carbide formed during the early stages of the tempering of martensite, which is afterwards changed by cementite [48-50]. APT revealed the formation of $\varepsilon$-carbide in both analysed martensitic structures; however, failed to identify $\varepsilon$-carbide in the bainitic structure austempered at $230{ }^{\circ} \mathrm{C}$ in the high silicon steel studied. These results are in agreement with previous research [28, $30,59-61]$ that demonstrated that the $\varepsilon$-carbide is only a precursor to the precipitation of cementite in lower bainite formed at temperatures higher than $350{ }^{\circ} \mathrm{C}$ in medium carbon low silicon steel, whereas, it has been detected at tempering temperatures lower than $500^{\circ} \mathrm{C}$ in high silicon steels. Likewise, X-ray synchrotron diffraction experiments reported elsewhere [29] revealed that both $\eta$ carbide and cementite are formed during bainite reaction at $220^{\circ} \mathrm{C}$ and $250{ }^{\circ} \mathrm{C}$ in Fe-1C-3Si-0.8Mn$0.4 \mathrm{Cr}($ wt.-\%) steel.

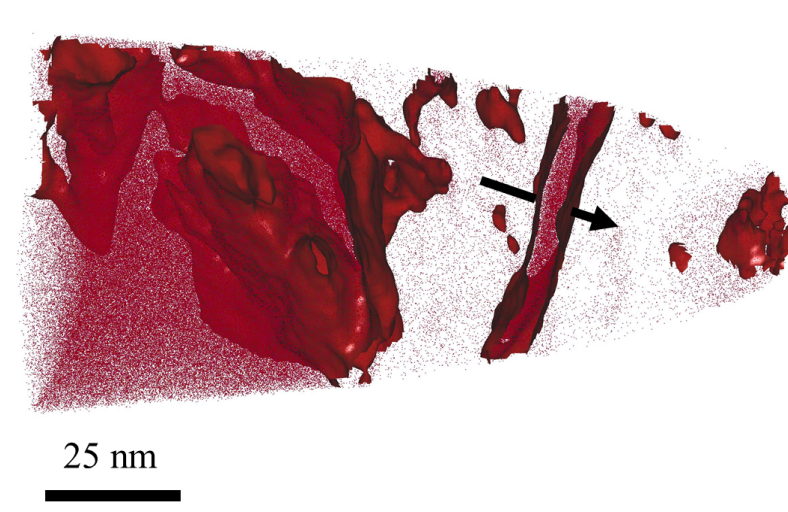

a)

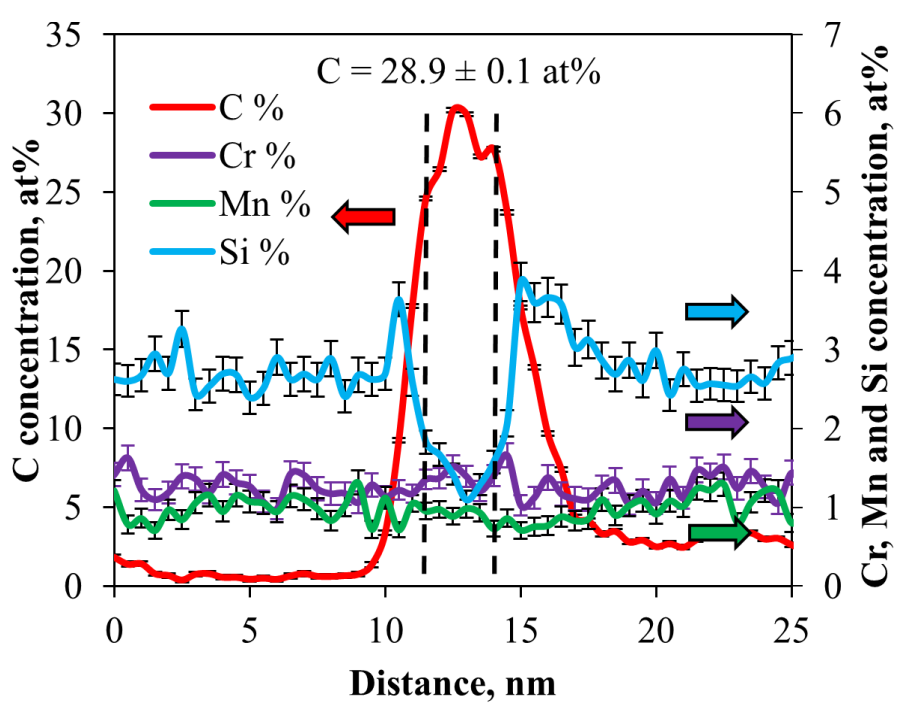

b)

Figure 7. (a) Carbon isoconcentration surfaces at 8 at. $\% \mathrm{C}$ superimposed with the carbon atom map, and (b) 1D concentration profile across a carbide particle, marked by the black arrow, in martensite after tempering at $350^{\circ} \mathrm{C}$ for 2 hours.

In addition, $K_{X}^{\alpha / \text { carbide }}$ data in Table 4 revealed that silicon partitioning did not take place after tempering at $230^{\circ} \mathrm{C}$, although chromium and manganese are slightly enriched within the detected carbide particles. APT results are in accordance to Chang and Smith [60] evidence, which showed $\varepsilon$-carbide precipitation without the partitioning of substitutional elements at an earlier stage of martensite tempering. As expected, silicon diffused out of the carbide after tempering at $350{ }^{\circ} \mathrm{C}$ and additional chromium and manganese enrichment is detected. Finally, carbide particles exhibiting 
substantial partitioning (higher silicon coefficients values and lower chromium and manganese coefficients values) in Table 4 were identified as primary cementite.

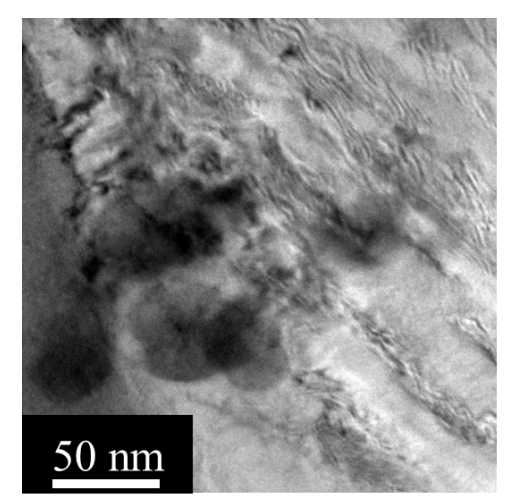

a)

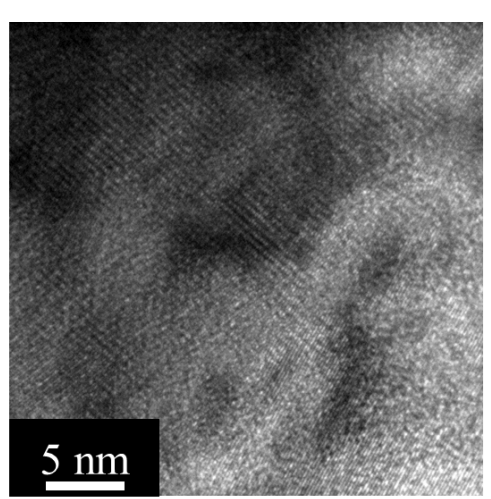

b)

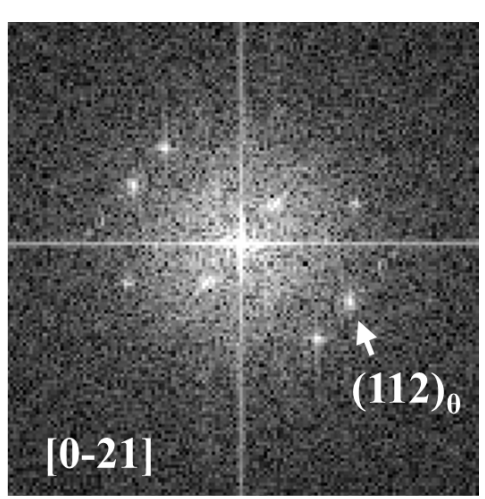

c)

Figure 8. (a) Bright Field, (b) HR-TEM images and (c) the Fourier-filtered transformed (FFT) diffraction pattern of a cementite carbide along the [0-21] $]_{\alpha}$ zone axis in martensite after tempering at $350^{\circ} \mathrm{C}$ for 2 hours.

Conclusively, TEM examination revealed the presence of nano-scale cementite particles on tempered structures as Figure 8 illustrates. Cementite carbide was found along the [0-21] zone axis in martensite, FFT diffraction pattern of the cementite was revealed by (112) cementite crystal plane as shown in Figure 8 (c). Apart of the complexity and heterogeneous distribution of carbon atoms at the nano-scale, the complementary use of APT and HR-TEM confirmed that an extensive nano-scale carbide precipitation would explain the higher hardness observed in martensitic structures when compared with bainitic structures treated at the same temperature.

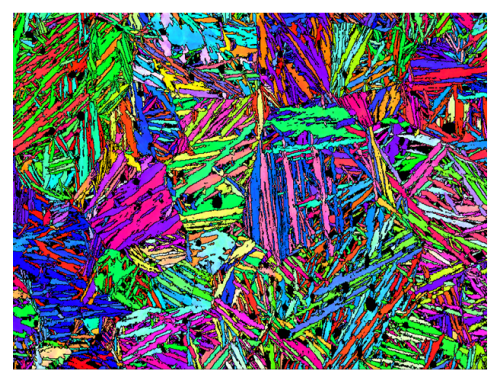

a)

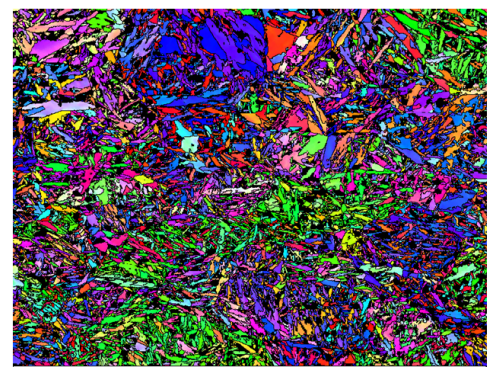

b)

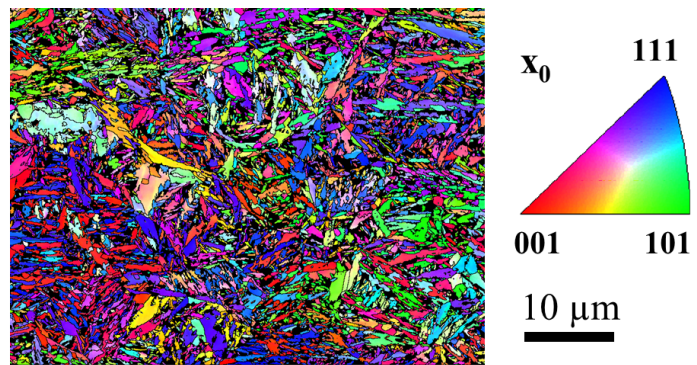

c)

Figure 9. Ferrite IPF maps for (a) bainitic structure; (b) Q\&P; and (c) Q\&T martensitic structures treated at $230{ }^{\circ} \mathrm{C}$.

\subsection{Crystallographic features of the structures}

On the other hand, differences on the crystallographic features that could explain the hardness values detected in bainitic and martensitic structures treated at the same temperature were 
investigated using EBSD. As mentioned above, crystallographic boundaries in both bainitic and martensitic microstructures come from the nature of the displacive transformation itself. As the inverse-pole figure (IPF) colour map images in Figure 9 illustrate, low temperature bainite and Q\&P and Q\&T martensitic structures exhibit the same hierarchical ferritic sub-structure of blocks, i.e., aggregates of plates of ferrite of equal variant or variants slightly misoriented, and packets, i.e., adjacent blocks with a $\left\{\begin{array}{llll}1 & 1 & 0\end{array}\right\}$ ferrite plane almost parallel to the same $\left\{\begin{array}{lll}1 & 1 & 1\end{array}\right\}$ austenite plane [17, 18]. It is clear from IPF maps that the bainitic microstructure exhibits coarser crystallographic ferritic grains. Thus, comparing their grain size distribution and the corresponding area that it occupies, significant differences arise between the crystallographic structure of bainitic and martensitic samples. Figure 10 confirms that the distribution is flatter for the bainitic microstructure with a larger portion of coarse ferritic grains.

Besides, the maximum length of crystallographic bcc grains in martensitic-like transformations is limited by the size of the prior austenite grain. Figure 11 shows the fcc IPF map and the corresponding bcc Euler map for bainite and Q\&T martensite treated at $230{ }^{\circ} \mathrm{C}$, where prior austenite grain boundaries are marked with white-dashed lines and prior austenite twin boundaries are marked with red-dashed lines. Prior austenite grains may show thermal twinning prior to either bainitic or martensitic transformation. The presence of twins limits the maximum length of the crystallographic ferritic grains within a single prior austenite grain to the length of the austenitic grain size as defined as a region where the austenite has approximately a unique orientation with an inner misorientation below $10^{\circ}$. 


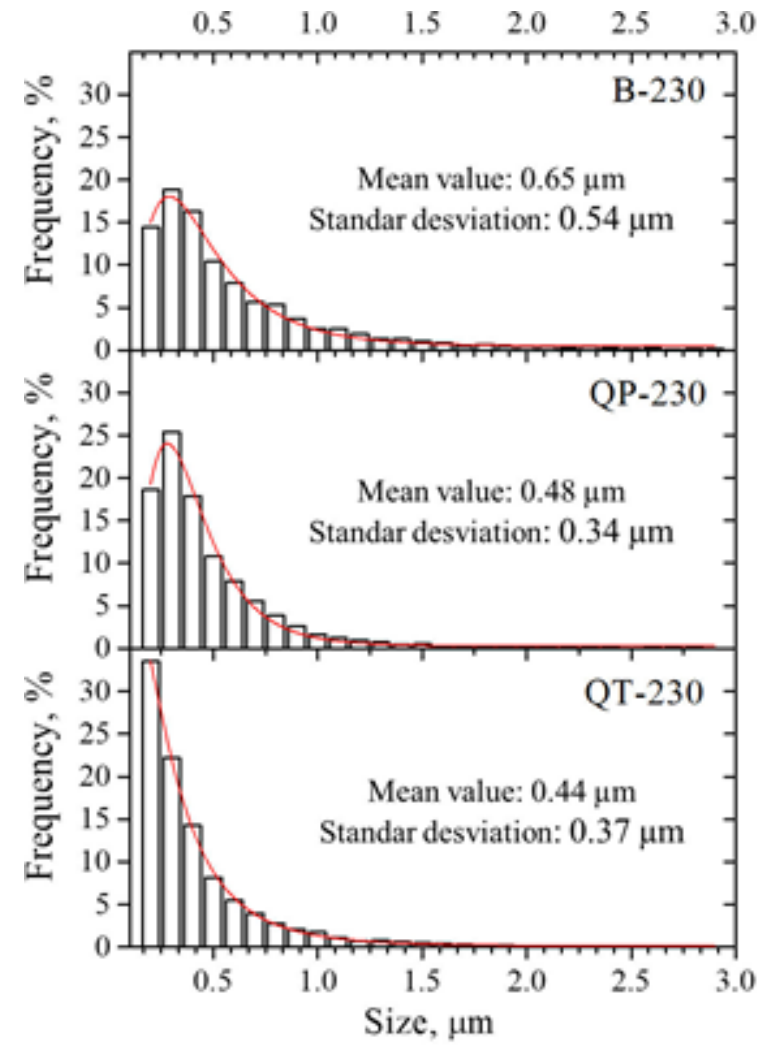

a)

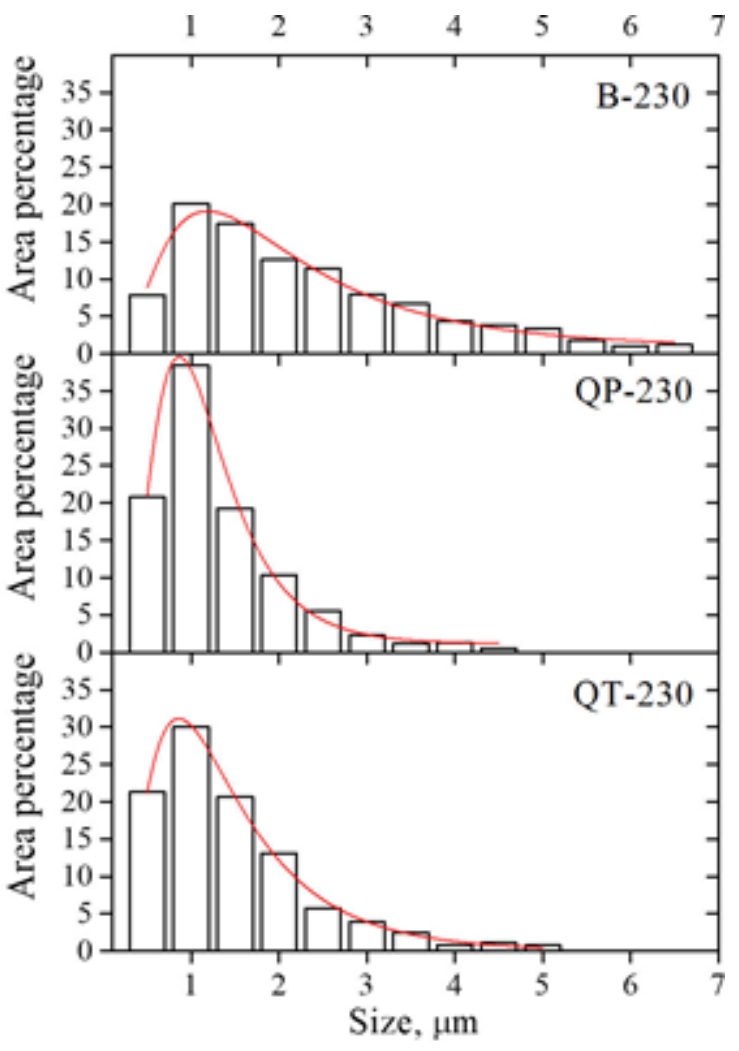

b)

Figure 10: (a) bcc crystallographic grain size frequency distribution expressed as the equivalent circle diameter of each grain area, and (b) corresponding area percentage distribution for bainitic and Q\&P and Q\&T martensitic structures treated at $230^{\circ} \mathrm{C}$. Red lines represent Lognormal fittings to the experimental distributions.

For the Q\&T martensitic structure, the fcc grain boundaries in Figure 11 (c) and (d) limit the growth of the bcc grains, but there seems not to be a relationship between sizes of the fcc and bcc grains. In contrast, Figure 11 (a) and (b) show that for the bainitic structure there is at least one bainite block that crosses the austenite grain from border to border. This is likely to be one of the first blocks to form, and it would further limit the length of the rest of the blocks by impingement events. In brief, the fcc grain size influences the maximum length of the bcc grain size in bainitic structures, while its influence upon the size of the bcc size in martensitic structures is not so clear. 


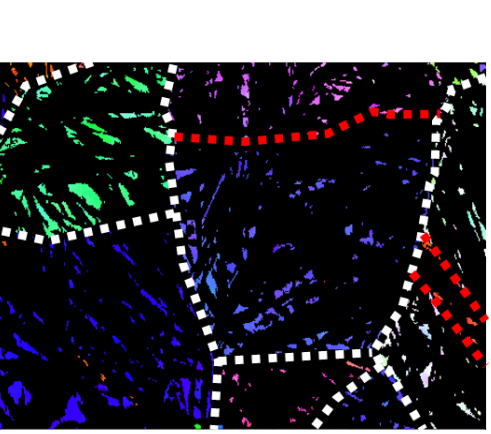

a)

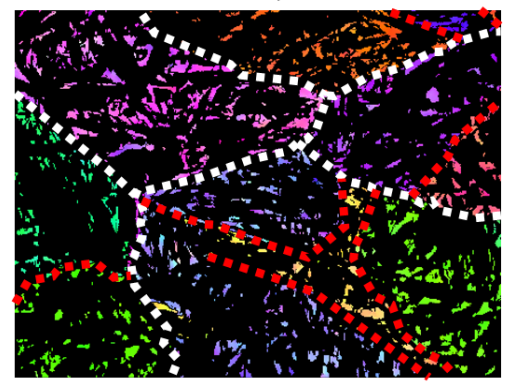

c)

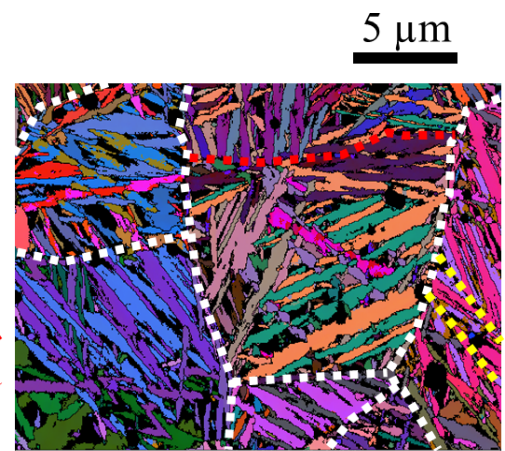

b)

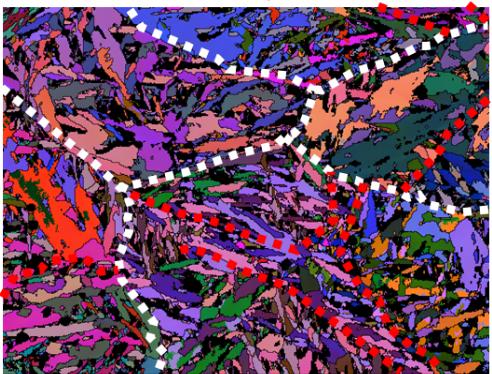

d)

Figure 11: Austenite IPF map and corresponding ferrite Euler map for (a) and (b) bainite and (c) and (d) Q\&T martensite treated at $230{ }^{\circ} \mathrm{C}$. Prior austenite grain boundaries are marked with whitedashed lines and prior austenite twin boundaries are marked with red-dashed lines.

In principle, bcc laths would be able to grow through the twins formed in the adjacent austenite, producing a reorientation of the lattice derived from the twins' orientation. Twins in the austenite, prior to bainite formation, are known to occur by shear on the (111) $\gamma$ twinning plane in the [11-2] $\gamma$ direction. Twins then have a common (111) $\gamma$ plane with the parent austenite, so the only packets that can be formed at both the parent and the twinned austenite are those having the twinning plane as the habit plane. 


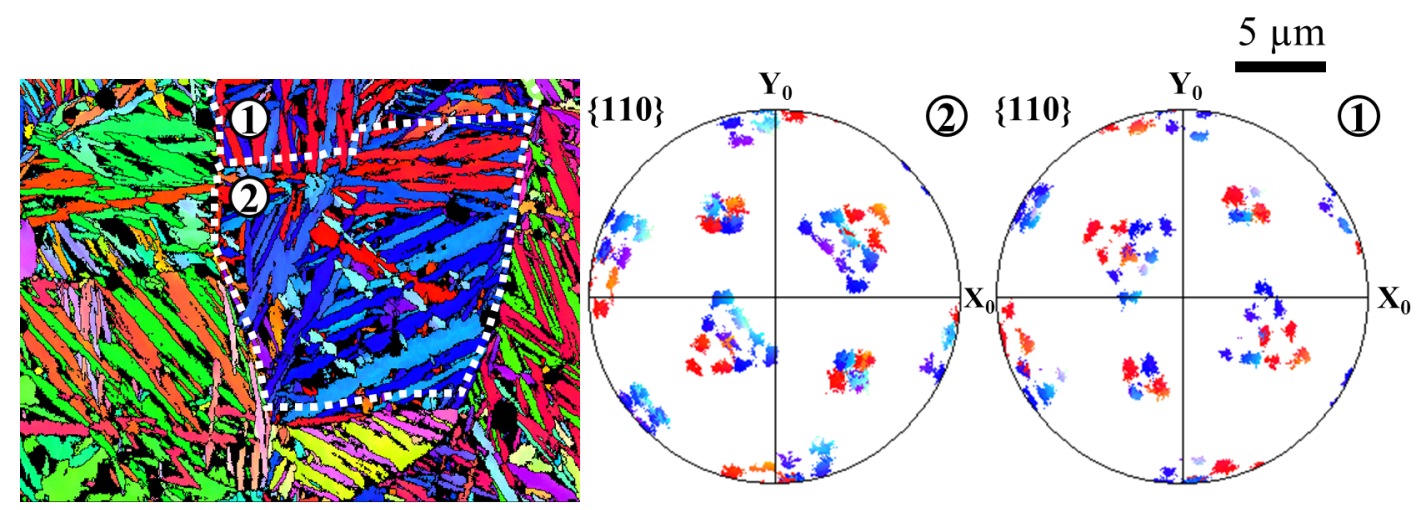

a)
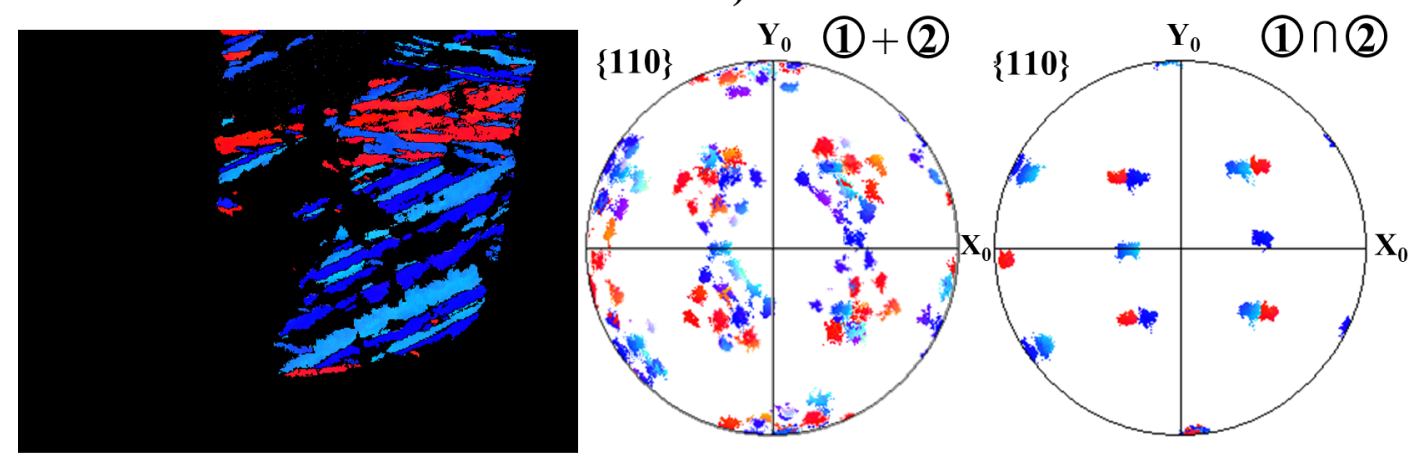

b)

Figure 12: (a) EBSD bcc IPF map for bainitic structure austempered at $230{ }^{\circ} \mathrm{C}$ and corresponding PFs for the fcc grains enclosed by the white-dashed lines (b) EBSD bcc IPF map for the same structure showing the bec variants common to both fcc grains shown in (a) and corresponding PFs.

Figure 12 (a) shows a bcc IPF map for bainitic structure austempered at $230{ }^{\circ} \mathrm{C}$ and corresponding PFs for the fcc grains (1) and (2) enclosed by the white-dashed lines and separated by the twin boundary indicated by the red-dashed line in Figure 11 (a). The orientation of three out of the four possible crystallographic packets is different at both sides of the twin boundary, as seen in the PFs. However, there is a set of variants with a common (111) $\gamma$ parallel plane with the parent austenite (the twinning plane). These variants have the same orientation at both sides of the twin boundary and are common to both fcc grains. PFs in Figure 12 (b) show that when all the variants in both grains are represented together (1)+(2), there is a set of variants coinciding in both grains (1) (2)). In the present case, common variants are not capable of growing through the twin boundary. This phenomenon has been repeatedly observed over all the microstructures analysed, supporting the given definition for the fcc grains. 
Table 5: Operators for the Kurdjumov-Sachs (K-S) orientation relationship between variants given in angle/axis notation.

\begin{tabular}{|c|c|c|c|c|c|}
\hline \multicolumn{6}{|c|}{ Kurdjumov-Sachs } \\
\hline Operator & Axis & Angle, deg & Operator & Axis & Angle, deg \\
\hline $\mathrm{O}_{0}$ & None & None & $\mathrm{O}_{12}$ & {$\left[\begin{array}{llll}5 & 6 & 24 & 49\end{array}\right]$} & 47.1 \\
\hline $\mathrm{O}_{1}$ & {$\left[\begin{array}{lll}1 & 0 & 1\end{array}\right]$} & 60.0 & $\mathrm{O}_{13}$ & {$\left[\begin{array}{lll}20 & 5 & 16\end{array}\right]$} & 50.5 \\
\hline $\mathrm{O}_{2}$ & {$\left[\begin{array}{lll}1 & 1 & 1\end{array}\right]$} & 60.0 & $\mathrm{O}_{14}$ & {$\left[\begin{array}{lll}16 & 20 & 5\end{array}\right]$} & 50.5 \\
\hline $\mathrm{O}_{3}$ & {$\left[\begin{array}{lll}1 & 1 & 1\end{array}\right]$} & 10.5 & $\mathrm{O}_{15}$ & {$\left[\begin{array}{lll}24 & 15 & 16\end{array}\right]$} & 50.5 \\
\hline $\mathrm{O}_{4}$ & {$\left[\begin{array}{lll}1 & 1 & 0\end{array}\right]$} & 60.0 & $\mathrm{O}_{16}$ & {$\left[\begin{array}{llll}2 & 1 & 56 & 4\end{array}\right]$} & 14.8 \\
\hline $\mathrm{O}_{5}$ & {$\left[\begin{array}{lll}1 & 1 & 0\end{array}\right]$} & 10.5 & $\mathrm{O}_{17}$ & {$\left[\begin{array}{lll}49 & 24 & 26\end{array}\right]$} & 47.1 \\
\hline $\mathrm{O}_{6}$ & {$\left[\begin{array}{lll}16 & 24 & 15\end{array}\right]$} & 50.5 & $\mathrm{O}_{18}$ & {$\left[\begin{array}{lll}0 & 4 & 9\end{array}\right]$} & 21.0 \\
\hline $\mathrm{O}_{7}$ & {$\left[\begin{array}{lll}1 & 0 & 1\end{array}\right]$} & 49.4 & $\mathrm{O}_{19}$ & 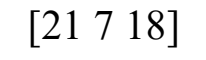 & 57.2 \\
\hline $\mathrm{O}_{8}$ & {$\left[\begin{array}{lll}1 & 1 & 1\end{array}\right]$} & 49.4 & $\mathrm{O}_{20}$ & [5 $\left.\begin{array}{lll}5 & 9\end{array}\right]$ & 20.6 \\
\hline $\mathrm{O}_{9}$ & {$\left[\begin{array}{lll}22 & 13 & 26\end{array}\right]$} & 57.2 & $\mathrm{O}_{21}$ & {$\left[\begin{array}{lll}9 & 9 & 5\end{array}\right]$} & 51.7 \\
\hline $\mathrm{O}_{10}$ & {$\left[\begin{array}{lll}13 & 22 & 26\end{array}\right]$} & 57.2 & $\mathrm{O}_{22}$ & {$\left[\begin{array}{lll}4 & 0 & 13\end{array}\right]$} & 20.6 \\
\hline $\mathrm{O}_{11}$ & 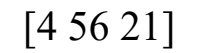 & 14.8 & $\mathrm{O}_{23}$ & 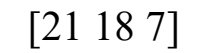 & 57.2 \\
\hline
\end{tabular}

In order to compare the characteristics of the crystallographic variants in bainitic and martensitic structures, a K-S OR has been assumed in all of them. To that aim, the orientations of the variants are first theoretically calculated; and the different types of misorientations between them are then deduced. An operator, expressed by the rotation axis that has the minimum rotation angle, identifies each misorientation between variants. Operators were calculated according to the grouped orientation variants according to Cyril Cayron [62-64] and are collected in Table 5 for the K-S ORs. Operators were identified in the neighbouring bcc grains of bainitic and Q\&P and Q\&T martensitic structures treated at $230{ }^{\circ} \mathrm{C}$ considering the K-S OR. Figure 13 shows the variant pairing tendencies represented by operator statistics in the microstructures studied. Q\&P and Q\&T martensitic structures show the same tendencies for the variant grouping, where the $\mathrm{O}_{2}, \mathrm{O}_{1}, \mathrm{O}_{4}, \mathrm{O}_{7}, \mathrm{O}_{5}$ and $\mathrm{O}_{20}$ are the most frequent operators. Table 6 collects the relevant variant groups for the K-S OR with their corresponding operators. In the case of Q\&P and Q\&T martensitic structures, the frequent operators are typical of close-packed plane (CPP) groups but a plate group component can also be identified, typical of the $\mathrm{O}_{20}$. The CPP group is constituted of six variants with a common (111) $\gamma$ parallel plane, and at the same time, it usually constitutes a morphological group (group of parallel laths). The plate group can be conceived as the union of two CPP groups from which the intersection close-packed direction (CPD) group is subtracted. It has been recently shown that plate 
groups observed in high-carbon martensite are actually parts of larger burst configurations which result from the combination of plate grouping with the twin-related $\mathrm{O}_{2}$ operator [65].

Table 6: Relevant groups of the K-S variants: Close-packed plane (CPP), plate and burst configuration groups expressed as sets of operators. See $[64,65]$ for more details

\begin{tabular}{ll}
\hline Group & Operators inside a group \\
\hline CPP & $\left\{\mathrm{O}_{0}, \mathrm{O}_{1}, \mathrm{O}_{2}, \mathrm{O}_{4}, \mathrm{O}_{5}, \mathrm{O}_{7}\right\}$ \\
Plate & $\left\{\mathrm{O}_{0}, \mathrm{O}_{7}, \mathrm{O}_{20}, \mathrm{O}_{21}\right\}$ \\
Burst configuration & $\left\{\mathrm{O}_{0}, \mathrm{O}_{2}, \mathrm{O}_{7}, \mathrm{O}_{20}, \mathrm{O}_{21}, \mathrm{O}_{4}, \mathrm{O}_{12}, \mathrm{O}_{19}\right\}$ \\
\hline
\end{tabular}

Variant grouping in the bainitic structure is slightly different, where $\mathrm{O}_{7}, \mathrm{O}_{1}, \mathrm{O}_{4}$ and $\mathrm{O}_{2}$ are the most frequent operators with a remarkable increase in the $\mathrm{O}_{7}$ operator. Thus, variants are also paired in CPP groups with no evidence of plate groups.

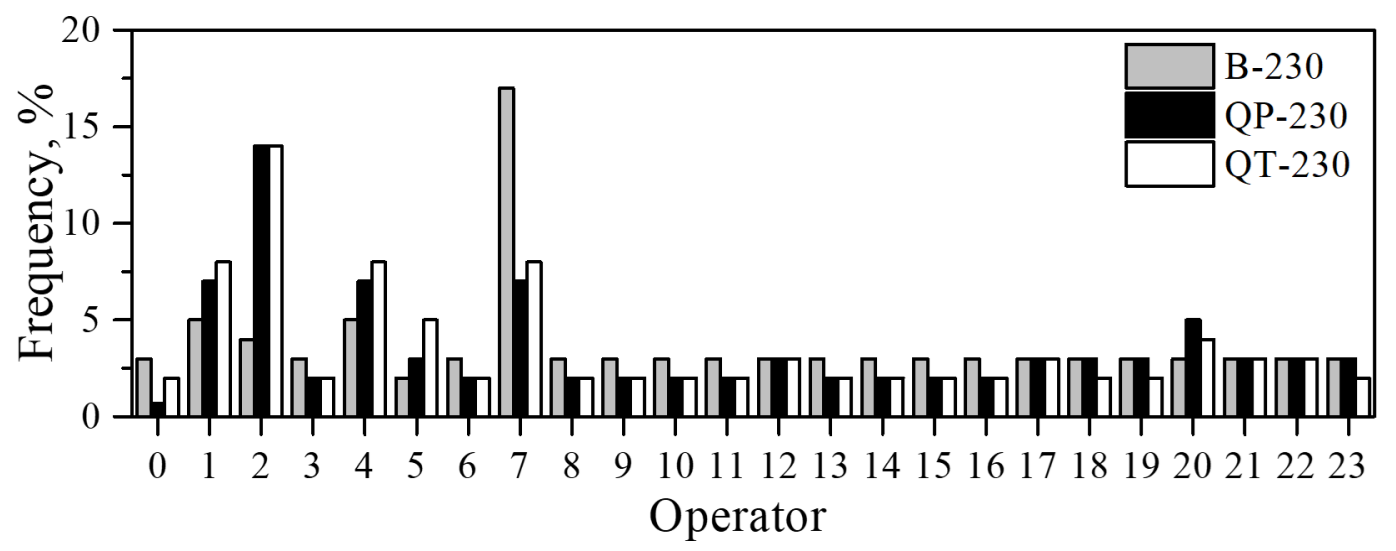

Figure 13: Operator histograms for bainitic and Q\&P and Q\&T martensitic structures treated at $230{ }^{\circ} \mathrm{C}$ according to the K-S orientation relationship. Operators (angle/axis rotations) are given in Table 5.

According to the one-step model for the formation of CPP packets [65], martensite nucleates with a Pitsch OR that leads to the formation of six K-S variants and to three N-W variants within a single CPP packet. The configuration of the six K-S variants is such that three pairs of variants are slightly misoriented by the operator $\mathrm{O}_{5}$. Each of these pairs of variants is close to a single $\mathrm{N}-\mathrm{W}$ variant and forms a block in the CPP packet. According to the model, each lath in the CPP packet is internally misoriented varying continuously from Pitsch to K-S and N-W ORs. The frequency of the operator $\mathrm{O}_{5}$ in Figure 13 is an indirect indication of the predominance of the K-S OR in the Q\&T martensitic 
structure, and to a lesser extent in the Q\&P structure, while its absence is a sign of prevalence of the $\mathrm{N}-\mathrm{W}$ OR in the bainitic structure.

For large driving forces, the difference in the activation energy for nucleation between variants becomes smaller and more variants are able to form. The self-accommodation is enhanced when plastic strain becomes larger by strengthening of austenite through lowering transformation temperature or increasing carbon content. For a fixed carbon content, bainite has a smaller driving force than martensite and accompanies a less degree of self-accommodation because bainite transformation takes place at higher temperature than martensite transformation [66].

Variant grouping in martensite is usually dependent on the carbon content of the steel. In low carbon steels (lower driving force), martensite forms CPP groups [67] while in high-carbon steels (higher driving force) martensite forms plate groups (parts of larger burst configurations) [65, 68]. Therefore, the coarser CPP structure of the bainitic structure is thought to be a consequence of the smaller driving force available for transformation.

\section{Conclusions}

Similar lath-like ferritic structures are observed after B, Q\&P and Q\&T treatment routines at low temperatures $\left(230^{\circ} \mathrm{C}\right)$. Austenite content is the same for the three treatments conditions; as well as structural characteristics such as the tetragonality in ferrite, microstrain and crystallite size of the structure measured by XRD. However, a maximum difference of $70 \mathrm{HV}$ is detected among them. In this sense, TEM and APT examination revealed the presence of carbides that explains the higher hardness detected in martensitic structures with similar retained austenite content. On the other hand, EBSD investigation revealed the crystallographic ferritic grains in the bainitic structure to be coarser than those in Q\&P and Q\&T martensitic structures treated at the same temperature of 230 ${ }^{\circ} \mathrm{C}$. Moreover, Q\&P and Q\&T martensitic structures show variant pairing into CPP and plate groups, whereas bainitic structures austempered at the same temperature shows pairing into CPP groups only. The larger driving force related to martensitic transformation in Q\&P and Q\&T structures is thought to be responsible for the crystallographic refinement and the presence of variant pairing into plate groups.

\section{Declarations of interest}

The authors declare that they have no known competing financial interests or personal relationships that could have appeared to influence the work reported in this paper.

\section{Data availability statement}


The raw/processed data required to reproduce these findings cannot be shared at this time as the data also forms part of an ongoing study.

\section{Acknowledgments}

This research was funded by the European Research Fund for Coal and Steel under the contracts RFSR-CT-2014-00016. APT was conducted at ORNL's Center for Nanophase Materials Sciences (CNMS), which is a U.S. DOE Office of Science User Facility. David de Castro acknowledges the Spanish Ministry of Science Economy and Competitiveness for his PhD research grant Ref. BES2017-080945. The authors acknowledge Dr Cyril Cayron for kindly providing ARPGE software for EBSD data analyses.

\section{References}

[1] J.G. Speer, D.V. Edmonds, F.C. Rizzo and D.K. Matlock, Partitioning of carbon from supersaturated plates of ferrite, with application to steel processing and fundamentals of the bainite transformation, Curr. Opin. Solid State Mat. Sci. 8 (2004) 219-237. https://doi.org/10.1016/j.cossms.2004.09.003

[2] D.V. Edmonds, K. He, F.C. Rizzo, B.C. De Cooman, D.K. Matlock and J.G. Speer, Quenching and partitioning martensite-A novel steel heat treatment, Mater. Sci. Eng. A. 438 (2006) 2534. https://doi.org/10.1016/j.msea.2006.02.133

[3] H. Liu, X. Lu, X. Jin, H. Dong and J. Shi, Enhanced mechanical properties of a hot stamped advanced high-strength steel treated by quenching and partitioning process, Scr. Mater. 64 (2011) 749-752. https://doi.org/10.1016/j.scriptamat.2010.12.037

[4] H.L. Yi, P. Chen, Z.Y. Hou, N. Hong, H.L. Cai, Y.B. Xu, D. Wu and G.D. Wang, A novel design: Partitioning achieved by quenching and tempering $(\mathrm{Q}-\mathrm{T} \& \mathrm{P})$ in an aluminium-added $\begin{array}{llllll}\text { low-density } & \text { steel, } & \text { Scr. } & \text { Mater. } & 68 & \text { (2013) }\end{array}$ https://doi.org/10.1016/j.scriptamat.2012.10.018

[5] J.G. Speer, E. De Moor and A.J. Clarke, Critical Assessment 7: Quenching and partitioning, Mater. Sci. Technol. 31 (2015) 3-9. https://doi.org/10.1179/1743284714Y.0000000628

[6] Y.-J. Li, X.-L. Li, G. Yuan, J. Kang, D. Chen and G.-D. Wang, Microstructure and partitioning behavior characteristics in low carbon steels treated by hot-rolling direct quenching and dynamical partitioning processes, Mater. Charact. $121 \quad$ (2016) 157-165. https://doi.org/10.1016/j.matchar.2016.10.005

[7] B.C. De Cooman, S.J. Lee, S. Shin, E.J. Seo and J.G. Speer, Combined Intercritical Annealing and Q\&P Processing of Medium Mn Steel, Metall. Mater. Trans. A. 48 (2017) 39-45. https://doi.org/10.1007/s11661-016-3821-z

[8] J. Speer, D.K. Matlock, B.C. De Cooman and J.G. Schroth, Carbon partitioning into austenite

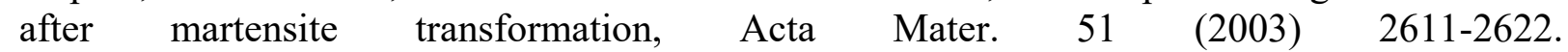
http://dx.doi.org/10.1016/S1359-6454(03)00059-4

[9] F.G. Caballero, H. Bhadeshia, K.J.A. Mawella, D.G. Jones and P. Brown, Design of novel high strength bainitic steels: Part 1, Mater. Sci. Technol. 17 (2001) 512-516. https://doi.org/10.1179/026708301101510348

[10] F.G. Caballero, H. Bhadeshia, K.J.A. Mawella, D.G. Jones and P. Brown, Design of novel high strength bainitic steels: Part 2, Mater. Sci. Technol. 17 (2001) 517-522. https://doi.org/10.1179/026708301101510357 
[11] F.G. Caballero and H.K.D.H. Bhadeshia, Very strong bainite, Curr. Opin. Solid State Mat. Sci. 8 (2004) 251-257. http://dx.doi.org/10.1016/j.cossms.2004.09.005

[12] F.G. Caballero, S. Allain, J. Cornide, J.D. Puerta Velásquez, C. Garcia-Mateo and M.K. Miller, Design of cold rolled and continuous annealed carbide-free bainitic steels for automotive application, Mater. Des. 49 (2013) 667-680. https://doi.org/10.1016/j.matdes.2013.02.046

[13] F.G. Caballero, C. Garcia-Mateo and M.K. Miller, Design of Novel Bainitic Steels: Moving from UltraFine to Nanoscale Structures, JOM. 66 (2014) 747-755. https://doi.org/10.1007/s11837-014-0908-0

[14] W.M. Garrison and M.K. Banerjee, Martensitic Non-stainless Steels: High Strength and High Alloy, in: (Eds.), 2016, pp. https://doi.org/10.1016/B978-0-12-803581-8.02519-4

[15] J. Christian, G. Olson and M. Cohen, Classification of Displacive Transformations : What is a Martensitic Transformation?, J. Phys. IV. 05 (1995) https://doi.org/10.1051/jp4:1995801

[16] E. Swallow and H.K.D.H. Bhadeshia, High resolution observations of displacements caused by bainitic transformation, Mater. Sci. Technol. 12 (1996) 121-125. https://doi.org/10.1179/mst.1996.12.2.121

[17] S. Morito, H. Tanaka, R. Konishi, T. Furuhara and T. Maki, The morphology and crystallography of lath martensite in Fe-C alloys, Acta Mater. 51 (2003) 1789-1799. http://dx.doi.org/10.1016/S1359-6454(02)00577-3

[18] N. Takayama, G. Miyamoto and T. Furuhara, Effects of transformation temperature on variant pairing of bainitic ferrite in low carbon steel, Acta Mater. 60 (2012) 2387-2396. https://doi.org/10.1016/j.actamat.2011.12.018

[19] H. Beladi, Y. Adachi, I. Timokhina and P.D. Hodgson, Crystallographic analysis of $\begin{array}{llllll}\text { nanobainitic } & \text { steels, } & \text { Scr. } & \text { Mater. } & 60 & \text { (2009) }\end{array}$ https://doi.org/10.1016/j.scriptamat.2008.11.030

[20] J.W. Christian, Accommodation strains in martensite formation, and the use of a dilatation parameter, Acta Metall. 6 (1958) 377-379. https://doi.org/10.1016/0001-6160(58)90077-4

[21] G.V. Kurdyumov and L.G. Khandros, On the "Thermoelastic" equilibrium on Martensitic transformations, Dokl. Akad. Nauk SSSR. 66 (1949) 211-214.

[22] L.C. Chang and H.K.D.H. Bhadeshia, Metallographic observations of bainite transformation mechanism, Mater. Sci. Technol. $11 \quad$ (1995) 105-108. https://doi.org/10.1179/mst.1995.11.2.105

[23] F.G. Caballero, H.-W. Yen, M.K. Miller, J.-R. Yang, J. Cornide and C. Garcia-Mateo, Complementary use of transmission electron microscopy and atom probe tomography for the examination of plastic accommodation in nanocrystalline bainitic steels, Acta Mater. 59 (2011) 6117-6123. http://dx.doi.org/10.1016/j.actamat.2011.06.024

[24] F.G. Caballero, M.K. Miller and C. Garcia-Mateo, Carbon supersaturation of ferrite in a nanocrystalline bainitic steel, Acta Mater. $58 \quad$ (2010) 2338-2343. https://doi.org/10.1016/j.actamat.2009.12.020

[25] F.G. Caballero, M.K. Miller, C. Garcia-Mateo, J. Cornide and M.J. Santofimia, Temperature dependence of carbon supersaturation of ferrite in bainitic steels, Scr. Mater. 67 (2012) 846849. https://doi.org/10.1016/j.scriptamat.2012.08.007

[26] R. Rementeria, J.D. Poplawsky, M.M. Aranda, W. Guo, J.A. Jimenez, C. Garcia-Mateo and F.G. Caballero, Carbon concentration measurements by atom probe tomography in the ferritic phase of high-silicon steels, Acta Mater. 125 (2017) 359-368. http://dx.doi.org/10.1016/j.actamat.2016.12.013

[27] C. Garcia-Mateo, J.A. Jimenez, H.W. Yen, M.K. Miller, L. Morales-Rivas, M. Kuntz, S.P. Ringer, J.R. Yang and F.G. Caballero, Low temperature bainitic ferrite: Evidence of carbon super-saturation and tetragonality, Acta Mater. 91 (2015) 162-173. http://dx.doi.org/10.1016/j.actamat.2015.03.018

[28] F.G. Caballero, M.K. Miller, S.S. Babu and C. Garcia-Mateo, Atomic scale observations of bainite transformation in a high carbon high silicon steel, Acta Mater. 55 (2007) 381-390. https://doi.org/10.1016/j.actamat.2006.08.033 
[29] R. Rementeria, J.A. Jimenez, S.Y. Allain, G. Geandier, J.D. Poplawsky, W. Guo, E. UronesGarrote, C. Garcia-Mateo and F.G. Caballero, Quantitative assessment of carbon allocation anomalies in low temperature bainite, Acta Mater. (2017) https://doi.org/10.1016/j.actamat.2017.05.048

[30] F.G. Caballero, M.K. Miller and C. Garcia-Mateo, Influence of transformation temperature on carbide precipitation sequence during lower bainite formation, Mater. Chem. Phys. 146 (2014) 50-57. https://doi.org/10.1016/j.matchemphys.2014.02.041

[31] R. Rementeria, C. Capdevila, R. Domínguez-Reyes, J.D. Poplawsky, W. Guo, E. UronesGarrote, C. Garcia-Mateo and F.G. Caballero, Carbon Clustering in Low-Temperature Bainite, Metall. Mater. Trans. A. 49 (2018) 5277-5287. https://doi.org/10.1007/s11661-018-4899-2

[32] A. Navarro-López, J. Hidalgo, J. Sietsma and M.J. Santofimia, Characterization of bainitic/martensitic structures formed in isothermal treatments below the Ms temperature, Mater. Charact. 128 (2017) 248-256. https://doi.org/10.1016/j.matchar.2017.04.007

[33] S.M.C. Van Bohemen, M.J. Santofimia and J. Sietsma, Experimental evidence for bainite formation below Ms in Fe-0.66C, Scr. Mater. 58 (2008) 488-491. https://doi.org/10.1016/j.scriptamat.2007.10.045

[34] T. Sourmail, F.G. Caballero, F. Moudian, D. De Castro and M. Benito, High hardness and retained austenite stability in Si-bearing hypereutectoid steel through new heat treatment design principles, Mater. Des. 142 (2018) 279-287. https://doi.org/10.1016/j.matdes.2018.01.035

[35] T. Sourmail, F. Moudian, M. Billet and M. Millot-Méheux, Influence of Si and Prior Heat Treatment on Long-Term Thermal Stability of 100Cr6-Type Bearing Steels, in: J. Beswick (Eds.), Bearing Steel Technologies: 11th Volume, Advances in Steel Technologies for Rolling Bearings, ASTM International, West Conshohocken, PA, 2017, pp. 192-209. https://doi.org/10.1520/STP160020160152

[36] H. Rietveld, A profile refinement method for nuclear and magnetic structures, J. Appl. Crystallogr. 2 (1969) 65-71. https://doi.org/10.1107/S0021889869006558

[37] D. Balzar and H. Ledbetter, Voigt-function modeling in Fourier analysis of size- and strainbroadened X-ray diffraction peaks, J. Appl. Crystallogr. 26 (1993) 97-103. https://doi.org/10.1107/S0021889892008987

[38] M.K. Miller, Atom Probe Tomography: Analysis at the Atomic Level, Kluwer Academic/Plenum, New York, 2000. https://doi.org/10.1007/978-1-4615-4281-0

[39] B. Gault, M.P. Moody, J.M. Cairney and S.P. Ringer, Atom Probe Microscopy, Springer, New York, 2012. https://doi.org/10.1007/978-1-4614-3436-8

[40] C. Garcia-Mateo, J.A. Jimenez, B. Lopez-Ezquerra, R. Rementeria, L. Morales-Rivas, M. Kuntz and F.G. Caballero, Analyzing the scale of the bainitic ferrite plates by XRD, SEM and TEM, Mater. Charact. 122 (2016) 83-89. http://dx.doi.org/10.1016/j.matchar.2016.10.023

[41] T. Ungár, Microstructural parameters from X-ray diffraction peak broadening, Scr. Mater. 51 (2004) 777-781. https://doi.org/10.1016/j.scriptamat.2004.05.007

[42] R.E. Smallman and K.H. Westmacott, Stacking faults in face-centred cubic metals and alloys, The Philosophical Magazine: A Journal of Theoretical Experimental and Applied Physics. 2 (1957) 669-683. https://doi.org/10.1080/14786435708242709

[43] G. Dini, R. Ueji, A. Najafizadeh and S.M. Monir-Vaghefi, Flow stress analysis of TWIP steel via the XRD measurement of dislocation density, Mater. Sci. Eng. A. 527 (2010) 2759-2763. https://doi.org/10.1016/j.msea.2010.01.033

[44] S. Morito, J. Nishikawa and T. Maki, Dislocation Density within Lath Martensite in Fe-C and Fe-Ni Alloys, ISIJ Int. 43 (2003) 1475-1477. https://doi.org/10.2355/isijinternational.43.1475

[45] H.K.D.H. Bhadeshia, Chapter 12: Mechanical Properties, in: H.K.D.H. Bhadeshia (Eds.), Bainite in Steels, Theory and Practice, Third Edition, Springer-Verlag, London, 2015, pp. 304. https://doi.org/10.1007/BF02656561

[46] F.G. Caballero, M.K. Miller and C. Garcia-Mateo, Atom Probe Tomography Analysis of Precipitation during Tempering of a Nanostructured Bainitic Steel, Metall. Mater. Trans. A. 42 (2011) 3660. https://doi.org/10.1007/s11661-011-0699-7 
[47] M.K. Miller, P.A. Beaven, S.S. Brenner and G.D.W. Smith, An atom probe study of the aging of iron- nickel- carbon martensite, Metall. Trans. A. 14 (1983) 1021-1024. https://doi.org/10.1007/bf02659850

[48] K.A. Taylor, L. Chang, G.B. Olson, G.D.W. Smith, M. Cohen and J.B.V. Sande, Spinodal decomposition during aging of Fe-Ni-C martensites, Metall. Trans. A. 20 (1989) 2717-2737. https://doi.org/10.1007/bf02670166

[49] K.A. Taylor, G.B. Olson, M. Cohen and J.B.V. Sande, $\{011\}$ Twinning in Fe-Ni-C martensites, Metall. Trans. A. 20 (1989) 2739-2747. https://doi.org/10.1007/bf02670167

[50] G.B. Olson and M. Cohen, Early Stages of Aging and Tempering of Ferrous Martensites, Metall. Trans. A. 14 (1983) 1057-1065. https://doi.org/10.1007/bf02659854

[51] L. Chang, A. Cerezo, G. Smith, D.W., M. Miller, K., M. Burke, G., S. Brenner, S., K. Taylor, A., T. Abe and G. Olson, B., Ageing of Fe-Ni-C Martensite, J. Phys. Colloques. 45 (1984) C9409-C409-416. https://doi.org/10.1051/jphyscol:1984968

[52] G. Miyamoto, K. Shinbo and T. Furuhara, Quantitative measurement of carbon content in FeC binary alloys by atom probe tomography, Scr. Mater. 67 (2012) 999-1002. https://doi.org/10.1016/j.scriptamat.2012.09.007

[53] J. Takahashi, K. Kawakami and Y. Kobayashi, Quantitative analysis of carbon content in cementite in steel by atom probe tomography, Ultramicroscopy. 111 (2011) 1233-1238. https://doi.org/10.1016/j.ultramic.2011.03.024

[54] S.S. Babu, K. Hono and T. Sakurai, APFIM studies on martensite tempering of Fe-C-Si-Mn low alloy steel, Appl. Surf. Sci. 67 (1993) 321-327. https://doi.org/10.1016/01694332(93)90333-7

[55] S.S. Babu, K. Hono and T. Sakurai, Atom probe field ion microscopy study of the partitioning of substitutional elements during tempering of a low-alloy steel martensite, Metall. Mater. Trans. A. 25 (1994) 499-508. https://doi.org/10.1007/bf02651591

[56] R.C. Thomson and M.K. Miller, Carbide precipitation in martensite during the early stages of tempering Cr- andMo-containing low alloy steels, Acta Mater. 46 (1998) 2203-2213. https://doi.org/10.1016/S1359-6454(97)00420-5

[57] F. Caballero, M. Miller, C. Garcia-Mateo, C. Capdevila and S. Babu, Redistribution of alloying elements during tempering of a nanocrystalline steel, Acta Mater. 56 (2008) 188-199. https://doi.org/10.1016/j.actamat.2007.09.018

[58] H.L. Yakel, Crystal structures of stable and metastable iron-containing carbides, Int. Met. Rev. 30 (1985) 17-44. https://doi.org/10.1179/imtr.1985.30.1.17

[59] H.K.D.H. Bhadeshia and D.V. Edmonds, The bainite transformation in a silicon steel, Metall. Trans. A. 10 (1979) 895-907. https://doi.org/10.1007/bf02658309

[60] L. Chang and G. Smith, D.W., The Silicon Effect in the Tempering of Martensite in Steels, J. Phys. Colloques. 45 (1984) C9-397-C399-401. https://doi.org/10.1051/jphyscol:1984966

[61] J.M. Howe, D.E. Laughlin, J.K. Lee, U. Dahmen and W.A. Soffa, Proceedings of an International Conference on Solid- Solid Phase Transformations in Inorganic Materials : Displacive Transformations vol. 1, 2005.

[62] C. Cayron, Groupoid of orientational variants, Acta Crystallographica Section A. 62 (2006) 2140. https://doi.org/10.1107/S010876730503686X

[63] C. Cayron, GenOVa: a computer program to generate orientational variants, J. Appl. Crystallogr. 40 (2007) 1179-1182. https://doi.org/10.1107/S0021889807048741

[64] C. Cayron, ARPGE: a computer program to automatically reconstruct the parent grains from electron backscatter diffraction data, J. Appl. Crystallogr. 40 (2007) 1183-1188. https://doi.org/10.1107/S0021889807048777

[65] C. Cayron, EBSD imaging of orientation relationships and variant groupings in different martensitic alloys and Widmanstätten iron meteorites, Mater. Charact. 94 (2014) 93-110. https://doi.org/10.1016/j.matchar.2014.05.015

[66] T. Furuhara, H. Kawata, S. Morito and T. Maki, Crystallography of upper bainite in Fe-Ni-C alloys, Mater. Sci. Eng. A. 431 (2006) 228-236. https://doi.org/10.1016/j.msea.2006.06.032 
[67] S. Morito, X. Huang, T. Furuhara, T. Maki and N. Hansen, The morphology and crystallography of lath martensite in alloy steels, Acta Mater. 54 (2006) 5323-5331. http://dx.doi.org/10.1016/j.actamat.2006.07.009

[68] A. Stormvinter, G. Miyamoto, T. Furuhara, P. Hedström and A. Borgenstam, Effect of carbon content on variant pairing of martensite in $\mathrm{Fe}-\mathrm{C}$ alloys, Acta Mater. 60 (2012) 7265-7274. http://dx.doi.org/10.1016/j.actamat.2012.09.046 